REVIEM

DO: $10.1002 /$ chem.200((will be filled in by the editorial staff))

\title{
Directed Remote Aromatic Metalations: Mechanisms and Driving Forces
}

\author{
David Tilly*, ${ }^{[a]}$ Jakob Magolan, $^{[b]}$ Jacques Mortier $^{[c]}$
}

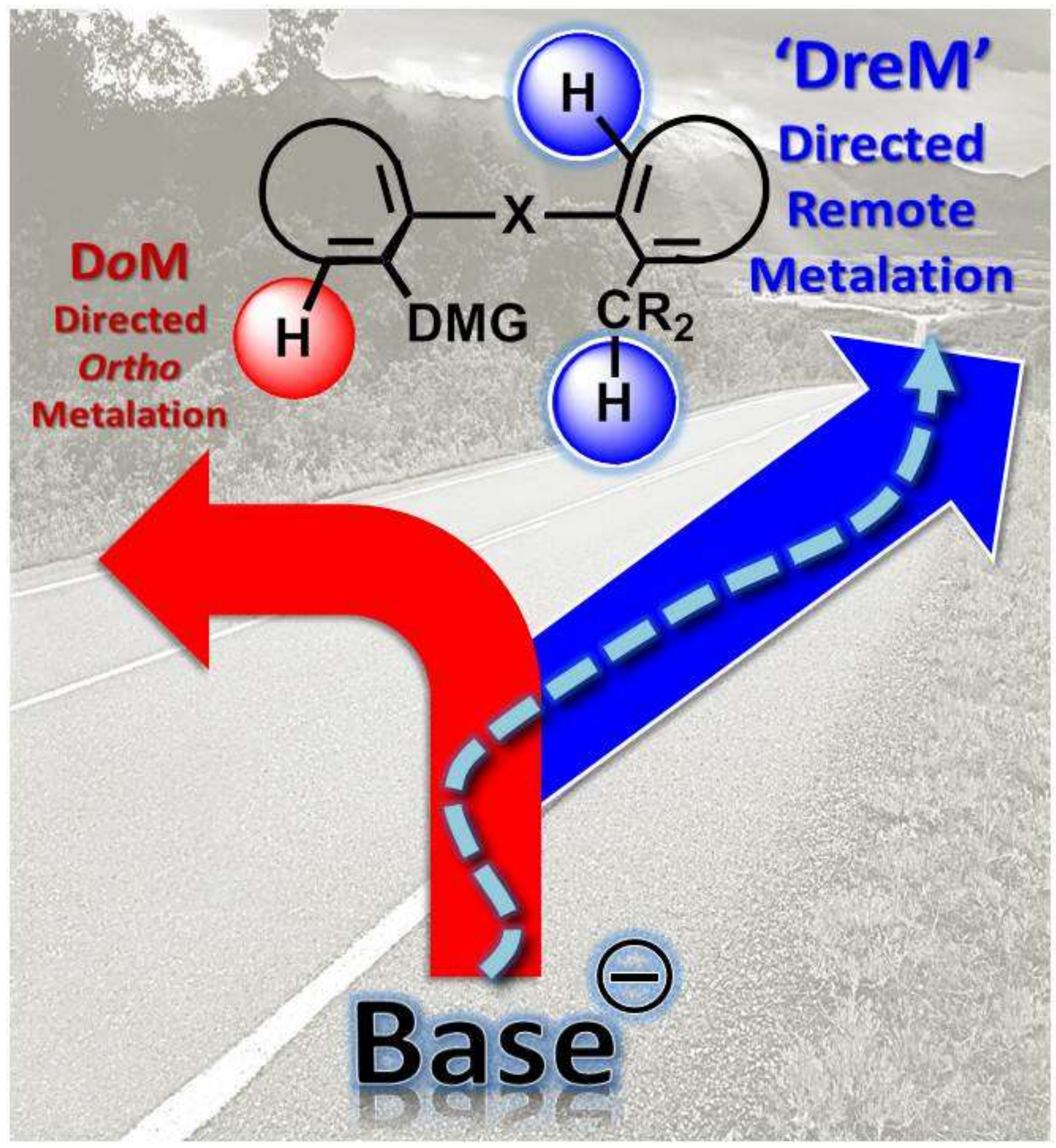


Abstract: Directed remote aromatic metalations are useful synthetic transformations allowing for rapid regioselective access to elaborate highly substituted carbocyclic aromatic and heteroaromatic systems. This review unravels the tangle of data reported on directed remote aromatic metalations. Through a careful analysis of critically selected examples, advanced rationalizations of remote metalation regioselectivities are presented. These extend beyond the complex induced proximity effect (CIPE).
Mechanisms, driving forces and parameters influencing remote metalations are discussed. An understanding of these metalation mechanisms enables more accurate predictability of justification of regiochemical outcomes of these useful synthetic transformations.

Keywords: directed metalation $\bullet$ remote metalation • lithiation $\bullet$ regioselectivity $\bullet$ reaction mechanisms

\section{Introduction}

Directed metalation has become a powerful tool for regioselective access to elaborate polysubstitued aromatic and heteroaromatic scaffolds. Gschwend, Rodriguez, ${ }^{[1]}$ Snieckus, ${ }^{[2]}$ Beak, $\left.{ }^{[2 b}, 3\right]$ Schlosser ${ }^{[4]}$ and Clayden ${ }^{[5]}$ have effectively illuminated the broad scope and utility of directed metalation strategies in synthesis. In this review, we focus our discussion on the rationalization of regioselectivity of metalations at remote positions relative to the directing species or directed remote metalations (DreM, Figure 1). Directed remote aromatic metalations have served as key transformations in the synthesis of natural products, active pharmaceutical ingredients and materials. ${ }^{[\mathrm{b}]}$ The mechanistic concept of complex induced proximity effect (CIPE), originally introduced in association with directed ortho metalations (DoM), was recently also utilized to rationalize DreM reactivity. ${ }^{[2 b]}$ However, a number of recent mechanistic studies of DreM have provided a deeper understanding of these transformations that extend beyond the scope of the CIPE model.

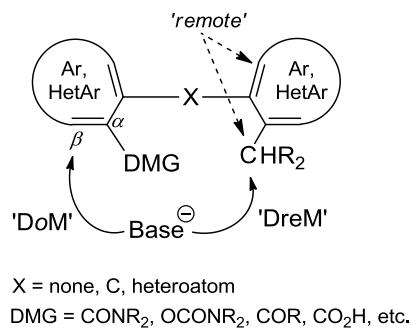

Figure 1. Directed ortho metalation (DoM) and directed remote metalation (DreM).

$[a]^{*} \quad$ Dr. D. Tilly

Eskitis Institute for Cell and Molecular Therapies Griffith University

Don Young Road, Nathan 4111, Queensland, Australia E-mail: dp.tilly@laposte.net

[b] Dr. J. Magolan

Department of Chemistry, University of Idaho Moscow, ID, USA

[c] Prof. J. Mortier

University of Le Mans UCO2M (UMR CNRS 6011)

Avenue Olivier Messiaen, 72085 Le Mans, Cedex 9, France
In this review, we strive to unravel the tangle of data reported on DreM using a mechanistic framework. Metalation regioselectivities are governed by a combination of kinetic and thermodynamic factors that are highlighted throughout the review. Through careful analysis of critically selected synthetic examples and mechanistic investigations, we offer insights intended to aid chemists in the prediction and rationalization of regioselectivity of directed metalations.

The mechanistic concepts applicable to directed metalations (CIPE, kinetically enhanced metalations, and overriding base mechanisms) will first be succinctly presented and then critically evaluated throughout the review for a series of substrate classes. Reaction mechanisms, and the consequent regioselectivity outcomes, depend on numerous factors including: the rigidity of the reactant skeletons, the nature and strength of the base, the coordinating, electrophilic and migrating properties of directing metalation groups (DMG), the stability of metalated products, the nature of the external electrophiles, the acidity of aromatic hydrogens, the kinetics of reactions among other parameters. DreM reactions are classified here into four substrate categories and each is considered in sequence (Figure 2, A-D). Firstly, DreM-intramolecular quench sequences (Figure 2, A and B) are discussed and significant driving forces are evaluated. In this category, directed remote aromatic and lateral metalation (B) on flexible biaryl structures bearing an electrophilic coordinating DMG is followed by intramolecular quench of remote anion with the DMG. Isomerization of the remote kinetic anion to the thermodynamically more stable species prior to electrophilic intramolecular quench is sometimes observed and translocation of a migrating DMG is also possible as part of the quench step. Secondly, remote metalations that are quenched by external electrophiles are analyzed (Figure 2, C and D). Trapping of remote anions with external electrophiles has been reported for non-electrophilic DMGs and for electrophilic coordinating DMGs when the rigidity of structures does not allow for subsequent intramolecular quench.

Lithiation on the meta and/or para positions of an arene with respect to the directing group, ${ }^{[6]}$ perilithiations, ${ }^{[7]}$ Parham cyclizations ${ }^{[8]}$ have been recently reviewed and are not discussed here. 
DreM with intramolecular quench by electrophilic DMG Electrophilic DMG $=\mathrm{CONR}_{2}, \mathrm{OCONR}_{2}, \mathrm{COR}, \mathrm{CO}_{2} \mathrm{H}$,

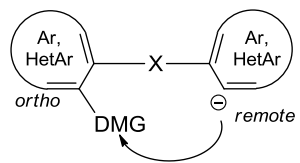

B Directed remote lateral metalation

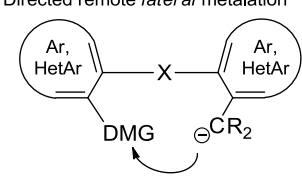

DreM with quench by external electrophiles

Non-electrophilic DMG $=\mathrm{NHR}, \mathrm{CN}, \mathrm{CH}=\mathrm{NR} \quad$ Rigid reactant skeletons with

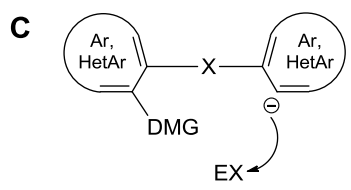
coordinating DMG (e.g. $\left.\mathrm{CO}_{2} \mathrm{H}\right)$

D

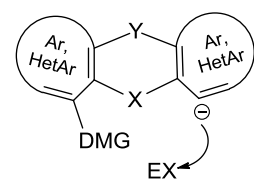

$E X=$ external electrophiles (e.g. Mel)

$\mathrm{X}, \mathrm{Y}=$ none, carbon, or heteroatom

Figure 2. Directed ortho metalation (DoM) and directed remote metalation (DreM).

\section{Mechanistic Concepts in Directed Metalation}

Metalation by organometallic bases in the vicinity of heteroatomcontaining functional groups often are rapid, regioselective and efficient. $^{[1-6]}$ The specific mechanistic pathways that allow the directing metalation group (DMG) to enhance the rate and regioselectivity of metalation within its vicinity remain the subject of debate. ${ }^{[2 b, 9]}$ Mechanism concepts that are commonly invoked to rationalize metalation regioselectivities are presented below.

Complex induced proximity effect (CIPE): The CIPE concept was introduced in organolithium transformations to rationalize the formation of kinetic rather than the anticipated thermodynamic products and the acceleration of seemingly unfavorable reactions. ${ }^{[1-3]}$ According to the CIPE model, a pre-lithiation event brings reactive groups into close proximity before the occurrence of subsequent intramolecular rate-determining metalation at the proximate site (Scheme 1). Over the years, the CIPE concept has provided guidance for synthetic development and rationalization of regioselective metalations including directed remote metalation (DreM). However, CIPE is commonly invoked without direct evidence of complexation to confirm "directed" metalations. CIPE was recently described by Snieckus and Beak as an efficient predicative tool useful as "heuristic model" regardless of the detailed reaction mechanism. ${ }^{[\mathrm{b}]}$

The involvement of CIPE in metalation should not be considered a general concept but rather requires investigation of the specific reaction and the nature of the substrate. In most cases, experimental data are subject to interpretation and a definite mechanism cannot be stated. ${ }^{[2 b, 9 b]}$ The literature offers abundant evidence for ligation of lithium to heteroatoms in ground states. ${ }^{[10]}$ The formation of pre-lithiation complexes between the organoalkali base and the reactant on the reaction pathway to directed metalation is supported by kinetic data, ${ }^{[11]}$ computational $^{[2 \mathrm{~b}]}$ and IR data ${ }^{[12]}$ in several transformations. ${ }^{[13]} \mathrm{A}$ CIPE, or lack thereof, can be manifested by divergent reactions.

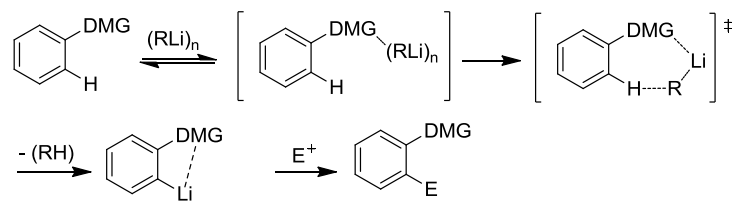

Kinetically enhanced metalation: Complex formation before rate limiting transition step is often presented as critical to preorganizing the species undergoing metalation. It is important to note that NMR, IR and X-ray studies can detect stable complexes which may not be on the reaction pathway. ${ }^{[14]}$ Any number of transiently formed species can precede the rate limiting step with none being kinetically relevant. ${ }^{[11 \mathrm{~d}, 15]}$ Schleyer has postulated a model in which complexation of the base and proton abstraction occur simultaneously. ${ }^{[16]}$ According to this model, directing and accelerating effects of the DMG are attributed to the existence of a stabilizing metal-substituent interaction at the rate determining transition structure rather than to a pre-lithiation complex. The term "kinetically enhanced metalation" was coined as an alternative to the 'complex-induced proximity effect' terminology. The kinetically enhanced metalation model focuses both on agostic interactions between lithium and the ortho hydrogen atoms lowering the energy at the transition state, and on favorable charge distribution in the transition structures (Figure 3). ${ }^{[16]}$

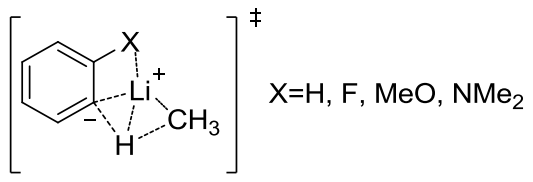

Figure 3. Four-center transition structure for DoM (Hommes and Schleyer, 1992). ${ }^{[16]}$

David Tilly graduated as Engineer from Ecole Nationale Supérieure de Chimie Rennes, and with a Master of Chemistry from Université de Rennes (France). In 2005, he completed a PhD in Organic Chemistry at Université du Maine (France) with Prof. J. Mortier (Directed metalations). After postdoctoral positions tackling the syntheses of complex diterpenes (Brisbane) and palladium catalysis (with Prof. V. Gevorgyan, University of Illinois, Chicago), he works since 2008 at ESKITIS (Australia) with Assoc. Prof. M. Coster, developping potent anticancer drugs.

Jakob Magolan received his BSc from Queen's University and PhD from the University of Western Ontario in Canada. His doctoral studies were in the field of heterocyclic natural products synthesis under the guidance of Prof. M. Kerr. After a postdoctoral fellowship at Griffith University, Australia, he began his independent academic career in 2010 at the University of Idaho. Dr. Magolan's research interests include: heterocyclic synthetic methods, heterogeneous catalysis, one-pot multi-step methodology, and anti-cancer medicinal chemistry.

Jacques Mortier obtained his PhD at Université de Rennes 1 (France) with Prof. J. Hamelin. After postdoctoral position at Northwestern University, USA (with Prof A. G. M. Barrett, 1987), he was appointed for 6 years as a senior scientist at RhônePoulenc, Agrochemical Research Centres of Lyons, France and Ongar, England. In 1994, he was appointed as Assistant Professor in Rennes, obtained his Habilitation in 1995, and was nominated member of Institut Universitaire de France in 1998. Since 1999, he is Professor at Université du Maine (Le Mans, France).
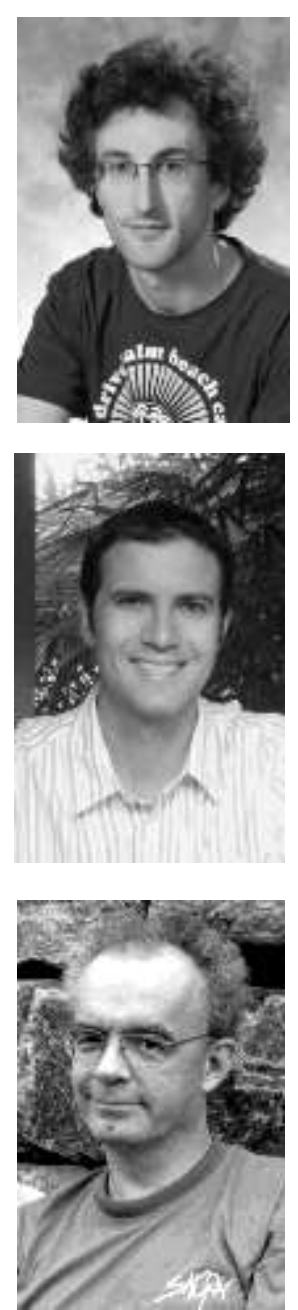
In our opinion, both theories (CIPE and kinetically enhanced metalation) furnish a complete picture if adequately combined. ${ }^{\text {[9a] }}$ Given the abundant literature evidence for coordination of lithium to heteroatoms in ground states (vide supra), it is very probable that initial approach of the base to the substrate is mediated by strong coordination with the electron-rich $\pi$-system of the DMG, leading to a pre-lithiation complex PLC (kinetic control, Figure 4). The directed ortho-lithiation was suggested to proceed by a twostep mechanism in which initial complexation is reversible whereas second step is rate determining. ${ }^{[9 b]}$ Not only must the reactants be brought together by chelation of the base with the DMG to form a pre-lithiation complex (kinetic control, Figure 4), they have to be held in exactly the right orientation relative to each other in the transition states to ensure that deprotonation can occur. Both of these factors raise the free energy of the system by lowering the entropy. Some energy also must be invested to begin breaking the $\mathrm{C}-\mathrm{H}$ bond so that the $\mathrm{C}-\mathrm{Li}$ bond can form. The directing and accelerating effect of substituents is likely due to the stabilization of both the initial complex and the transition structure. The metal is involved in partial bonds and coordination by the DMG becomes stronger in the transition state than in the initial complex. As a result, complexation increases the rate of reaction by providing a new mechanism with lower activation energy (Ea). There are two transition states, each with its own activation energy (Ea1 and Ea2). The overall activation energy is the difference in energy between the reactant state and the highest energy transition state (Ea). Notably, the geometries of precursor complex and transition structure can be radically different.

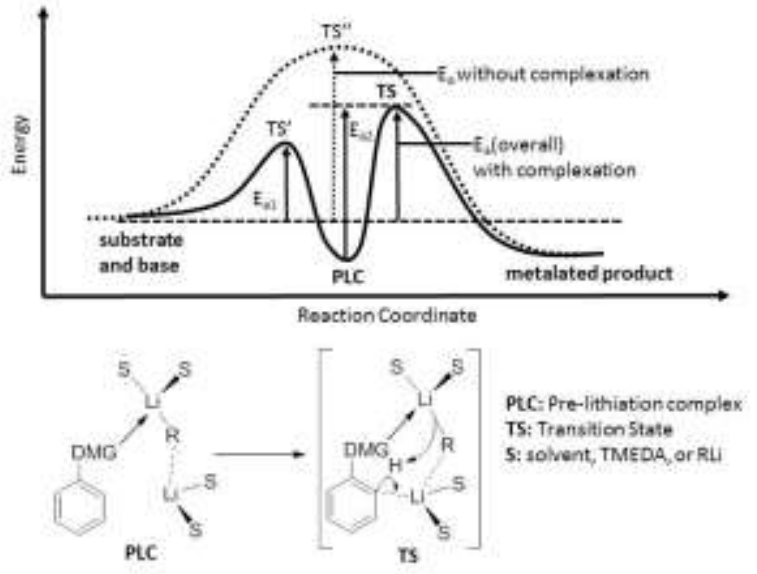

Figure 4. Qualitative energy diagram for directed metalations. ${ }^{\text {[a] }}$

The relative basicities of $n$-BuLi in cyclohexane as a function of the addition of increasing increments of THF or TMEDA were recently assessed by kinetics studies and ${ }^{7} \mathrm{Li}$ NMR studies. ${ }^{[17]} \mathrm{A}$ gradual controlled increase in the basicity of $n$-BuLi was observed with increasing increments of THF or TMEDA. Relationships of the basicity in the varied media to the three oligomeric forms of $n$ BuLi were proposed. Complexations of metal bases to Lewis basic DMGs may likely have a similar effect on the relative basic properties intra-aggregate.

Overriding base mechanism: The overriding base mechanism suggests that some strong bases react preferentially with relatively acidic aromatic protons without pre-coordination to a substituent. ${ }^{[1,}$ 11d] The mechanism depends solely upon the enhanced acidity of the ortho hydrogens resulting from strong electronegativities of certain DMGs such as halo, trifluoromethyl, and cyano moieties. Inductive effects were advantageously exploited in the metalation of arenes bearing two heteroatom-based DMGs. Weakly solvated organolithium reagents preferentially exploit the coordinative ability of a DMG whereas fully complexed bases (with $t$-BuOK or PMDTA) do not complex weaker coordinating functional groups/ligands but rather selectively target positions where a negative charge can be most efficiently stabilized blah ${ }^{[4,18]}$

\section{DreM: Early Mechanistic Interpretations}

Directed remote metalation methodology is often presented as an extension of directed ortho metalation whereby the directing ability of DMG apparently reaches beyond the ortho hydrogens. ${ }^{[2 b]}$ The labels 'directed remote' metalation or 'throughspace' induced metalation describe metalations assisted by a substituent at position that is 'formally' remote from, but conformationally in proximity to a functional group that is likely to be complexed by a metalating agent (Figure 2). ${ }^{[b]}$ The study of DreM has occurred at a slower pace that of DoM as positions ortho to directing groups appear to be more readily metalable as dictated by CIPE. ${ }^{[2]}$

Early examples of directed remote aromatic metalations were reported on biarylic structures bearing amino groups (vide supra). ${ }^{[19]}$ Cartoon and Cheeseman also reported the directed lithiation of 1-(2'-carboxyphenyl)pyrrole, 1, with LDA to form 9keto-9H-pyrolo[1,2-a]indole, 3 , via the "anionic equivalent of the Friedel-Crafts cycloacylation.' (Scheme 2). ${ }^{[20]}$ The authors suggested the metalation was "directed by the possibly chelated lithium cluster present on the adjacent ring and by the relative acidity of pyrrole hydrogens." ${ }^{\text {,20-21] }] ~ D r e M ~ w i t h ~ n u c l e o p h i l i c ~}$ intramolecular quench of biarylcarboxamides was reported by Snieckus to afford exclusively fluorenones. ${ }^{[22]}$

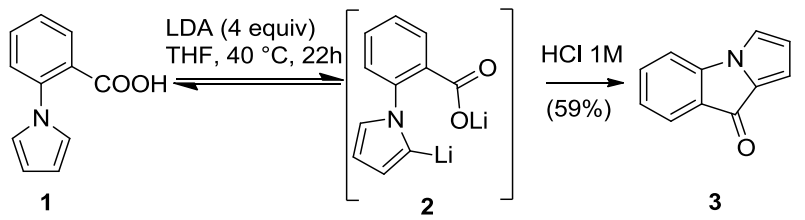

Scheme 2. Early example of DreM with cyclization directed by carboxyl DMG (Cartoon and Cheeseman, 1981) $^{[20]}$

DreM methodology has been developed, primarily by Snieckus and co-workers, for a variety of directing groups and substrates. ${ }^{[23]}$ The versatility and practicality of DreM in synthesis was established by a seminal work of Snieckus: DreM proved very dependable without extensive mechanistic insights and acted as a conduit for the synthesis of numerous natural products including dengibsinin, ${ }^{[22]}$ 6-deoxydengibsin, ${ }^{[24]}$ dengibsin, ${ }^{[25]}$ lmeluteine, ${ }^{[23 b]}$ defucogilvocarin, ${ }^{[26]}$ piperolactam, ${ }^{[27]} \beta$-lapachone, ${ }^{[28]}$ plicadin, ${ }^{[29]}$ eupolauramine, ${ }^{[30]}$ gymnopusin $\mathrm{C},{ }^{[31]}$ triazadibenzo[cd,f]azulen7(6H0-one, ${ }^{[32]}$ salcomine ${ }^{[33]}$ and homoschatoline ${ }^{[33]}$ (Figure 5). 


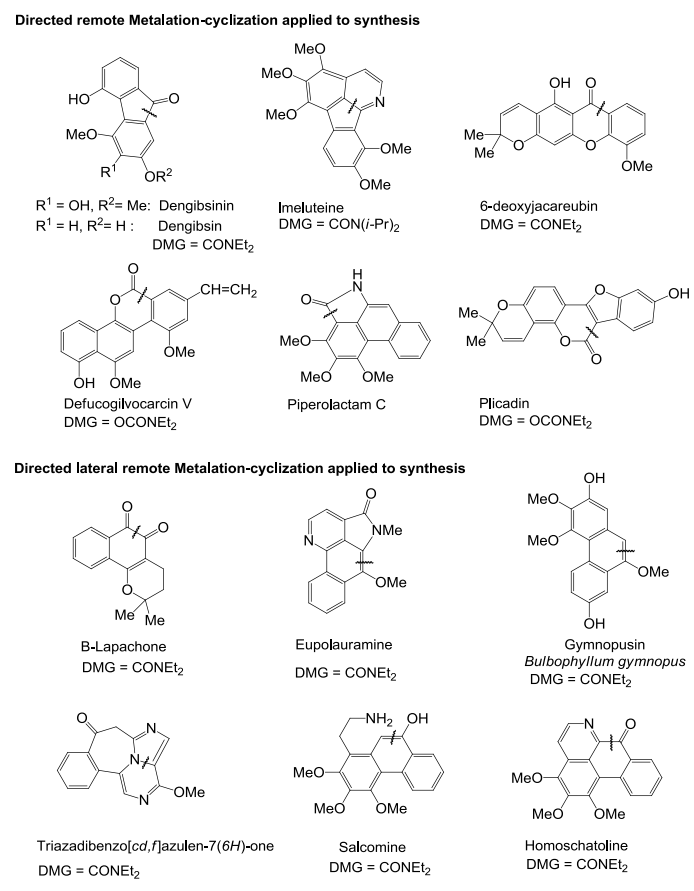

Figure 5. Examplex of complex compounds accessed using DreM-cyclization.

Notably, most DreM reactions have been reported on flexible biaryl structures bearing electrophilic DMG yielding products that result from intramolecular quench of remote anions by the DMG only (Figure 2, A and B). There are few reported examples of quench of a remote anion by external electrophiles. These contain exclusively non-electrophilic DMGs or rigid substrate scaffolds that do not allow for intramolecular quench (Figure 2, C and D). The apparent selective formation of products from intramolecular quench of remote anions was initially interpreted as indirect evidence for efficient regioselective remote metalation first steps. [22-33] The remote regioselectivity of metalation was rationalized initially through the involvement of CIPE only. ${ }^{[2 \mathrm{~b}]}$ As illustrated in Figure 6, a $\mathrm{DMG}^{2}$ functionality was proposed to convert the 'remote' site into a hypothetical 'ortho' site for metalation on the adjacent ring.

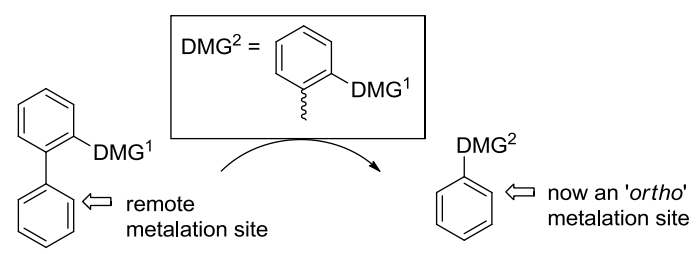

$\mathrm{DMG}^{1}=\mathrm{CONR}_{2}, \mathrm{OCONR}_{2}, \mathrm{COR}, \mathrm{CO}_{2} \mathrm{H}, \mathrm{NHR}, \mathrm{CN}, \mathrm{CH}=\mathrm{NR}$

Figure 6. CIPE used to explain DreM on 2-DMG-biphenyl substrates.

This rationalization is problematic as CIPE is already used to account for ortho metalation regioselectivities on biaryl substrates. ${ }^{[34]}$ Given that the hydrogens in the ortho position relative to the heteroatom containing $\mathrm{DMG}^{1}$ (Figure 6) are more inductively activated and closer to the Lewis basic group than remote hydrogens, it is inadequate to use CIPE alone to rationalize to rationalize both regioselectivities (ortho and remote) on biarylic reactants? Moreover, experimental conditions that favor CIPE (alkyllithium reagents, low temperatures) are known to lead to $\mathrm{D} o \mathrm{M}^{[34]}$ whereas conditions that are likely to disfavor coordination to DMG (use of amide bases and ligands such as HMPA, tBuOK, higher temperature) preferentially lead to DreM. ${ }^{[22-33,35]}$ In the following sections, we aim to clarify the driving forces of remote aromatic metalations by highlighting relevant recent studies. The various DreM mechanisms are classified according to structural features of the reactants.

\section{DreM with Intramolecular Quench by Electrophilic DMG}

Directed remote metalations on flexible biarylic structures bearing non migrating electrophilic DMGs such as carbamide, carboxylate, or ester moieties form cyclic compounds as sole products. ${ }^{\text {[22-33, 35a] }}$ To date, attempts to trap remote metalated species on these systems with external electrophiles has failed. Cyclized products result from intramolecular nucleophilic substitutions of remote anionic species onto the electrophilic DMG (Figure 2, A and B). With an electrophilic migrating DMG such as a carbamate, intramolecular quench of preformed remote anions is possible on both rigid or flexible substrate skeletons. In the following sections, the various mechanisms of DreM with intramolecular quench are unfolded. Driving forces are highlighted and the parameters allowing for efficient remote metalations are discussed.

\section{In Situ Quench Mechanisms and Influence of the Nature of the Base}

Mechanisms of DreM-cyclizations were recently investigated on 2-biphenylcarboxylic acid $^{[35 a]}$ and 2-biphenylamide. ${ }^{[36]}$ These representative substrates were chosen for mechanistic studies since their scaffolds are prototypes of DreM-intramolecular quench methodology, thus mechanistic information gathered on DreM-cyclization of such structures can potentially be extended to more complex analogous reactants. These fundamental studies are presented below. In contrast to initial assumptions, DreM reactions were found to be non-regioselective. ${ }^{[35-36]}$ That is, metalation at the ortho position is kinetically favored (via CIPE) even when cyclized compounds from DreM are the only products isolated. DMGs act as intramolecular electrophiles in a similar manner to in situ quench (ISQ) techniques. ${ }^{[37]}$ The flexibility of the reactant structures or/and the migratory ability of electrophilic substituents (i.e. carbamates) allow for rapid intramolecular quench of remote anions. Furthermore, DreM mechanisms are found to be base-dependent.

DreM-intramolecular quench under irreversible metalation conditions. Example of 2-biphenylcarboxylic acid and LiCKOR: The first thorough mechanistic study of directed remote aromatic metalation was reported on 2-biphenylcarboxylic acid (Scheme 3). ${ }^{[35]}$ Substrate $\mathbf{4}$ undergoes metalation in the immediate vicinity of the carboxylate substituent (C3) when treated with s-butyllithium in THF. ${ }^{[34 \mathrm{c}, 34 \mathrm{~d}]}$ In contrast, treatment of 4 with the LICKOR superbase ( $n$-butyllithium/tBuOK) ${ }^{[38]}$ affords the fluorenone 7 (76\% in benzene at $\left.60{ }^{\circ} \mathrm{C}\right)$ after hydrolysis. This appears to be a regioselective remote metalation. Furthermore, the use of amide bases did not result in remote metalation of $\mathbf{4}$, presumably because the carboxylate moiety does not activate remote positions through "through-bond" electronic activation to a sufficient degree. A stronger base is a requirement. Importantly, LiCKOR base irreversibly metalates reactants. 


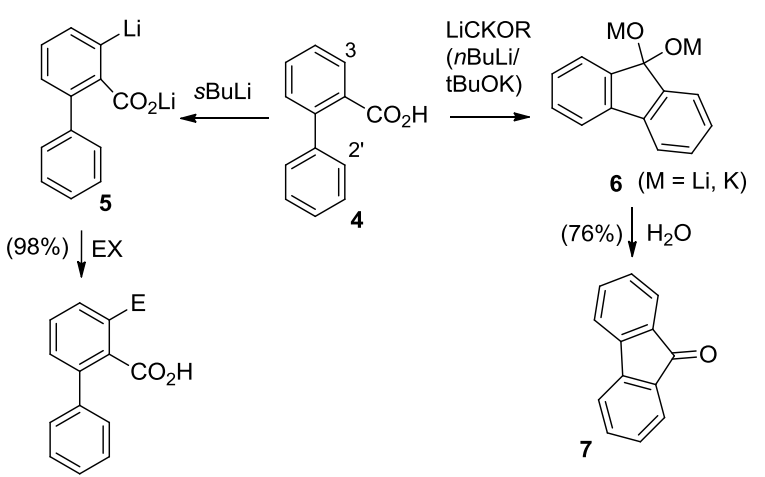

Scheme 3. Optional site selectivity in metalation on 2-biphenylcarboxylic acid. ${ }^{[34 c, 35 a]}$

Isotope labelling experiments established that LiCKOR metalates non-regioselectively in both the ortho $(\mathrm{C} 3)$ and remote (C2') positions of 4 (Scheme 4). The ortho lithiated species 5 (obtained by treatment of $\mathbf{4}$ with $s \mathrm{BuLi}$ ) is stable at room temperature and does not equilibrate with the remote anionic species 8. Following metalation at remote ( $\mathrm{C}^{\prime}$ ') positions the carboxylate moiety $\mathbf{8}$ reacts with the remote $\mathrm{C} 2$ ' aryl anion via fast and irreversible nucleophilic cyclization to form a stable tetrahedral gem-dialkoxide, intermediate $\mathbf{6}$, prior to hydrolysis. ${ }^{[35 a]}$ This nucleophilic cyclization ultimately drives the reaction towards the formation of fluorenones exclusively. No measurable build-up of a remote anionic species $\mathbf{8}$ indicates a rate-limiting remote lithiation followed by a rapid annulation. Strong support for a fast and irreversible cyclization step is found in the literature. When 2'-bromo-2-biphenylcarboxylic acid, 2'-bromo-2biphenyloxazoline, ${ }^{[39]}$ and 1-(2'-bromophenyl)pyrrole-2carboxylic acid $^{[20]}$ were subjected to halogen-lithium exchange, the 2'-lithiated species could not be trapped by an external electrophile in any case. Within the past decades, reported attempts to trap an anion remote from electrophilic DMGs during DreM-cyclization sequences have repeatedly failed. [22-33, 35] Ortho metalated species 5 also leads to the cyclized structure $\mathbf{9}$ upon exposure to LiCKOR. Notably, directing metalation properties were also found for gem-dimetalo dialkoxide $\left[\mathrm{C}(\mathrm{OM})_{2}\right]^{[35 \mathrm{a}]}$

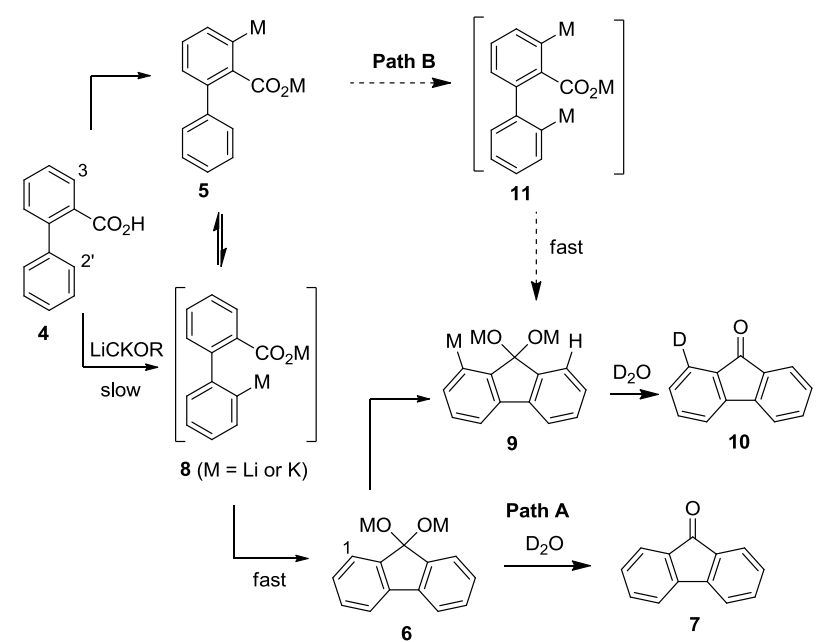

Scheme 4. Directed remote metalation of 2-biphenylcarboxylic acid (4) with LiCKOR. ${ }^{[35 a]}$

In the above example, the involvement of CIPE is unclear and an overriding mechanism being possible given that LiCKOR is able to efficiently metalate naked benzene rings. ${ }^{[38]}$ The carboxylate moiety might also compete with $t \mathrm{BuOK}$ as a solvation ligand. In such case, mixed aggregates would generate agostic hydrogen-metal interactions in the intermediate complexes ${ }^{[40]}$ and delivery of the base by prior coordination to the carboxylate would assist metalation in a non-regiospecific fashion. These results neither require nor exclude the existence of pre-equilibrium complexes and aggregates. Whereas $5(\mathrm{M}=\mathrm{Li})$ is stable at room temperature, a fast $\mathrm{Li}-\mathrm{K}$ permutation may allow the equilibrium between 5 and 8 to be effective. ${ }^{[41]}$

DreM-nucleophilic cyclization under reversible metalation conditions. Example of $\mathrm{N}, \mathrm{N}$-dialkylbiphenyl-2-carboxamide and amide base: Another example of optional site selectivity was reported on $N, N$-diethyl-2-biphenylcarboxamide 12 (Scheme 5). Metalation of 12 with sBuLi/TMEDA in THF at $-78{ }^{\circ} \mathrm{C}$ occurs at the ortho position (DoM, via CIPE). ${ }^{[34 \mathrm{a}, 34 \mathrm{~b}]}$ In contrast, subjection of $\mathbf{1 2}$ to LDA at $0{ }^{\circ} \mathrm{C}$ to RT yields fluorenone 7 (DreM). ${ }^{[31,35 a]}$ In this case, the mild amide base reversibly metalates the substrate allowing for series of equilibria between lithiated species during the reaction. ${ }^{[42]}$

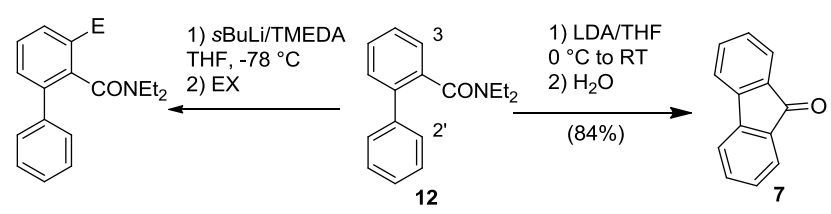

Scheme 5. Metalations of 2-biphenylcarboxamide (12) with lithium bases. ${ }^{[22,34 a, 34 b, 36]}$

Isotope labelling experiments indicated that LDA metalation of 12 is non-regioselective, ${ }^{[36]}$ with metalation at the ortho position being favored in accordance with the CIPE model. When LDA and TMSCl were premixed in THF solution $\left(-78{ }^{\circ} \mathrm{C}\right)$ prior to addition of 12 (ISQ), 14 was formed exclusively (65\%, Scheme 6). This suggests kinetic control predominates over thermodynamic acidity of $\mathrm{C}-3 \mathrm{H}$ compared to $\mathrm{C}-2^{\prime} \mathrm{H}$ in $\mathbf{1 2}$. Ortho-lithiated species $\mathbf{1 3}$, formed by reaction of $\mathbf{1 2}$ with $s \mathrm{BuLi} / \mathrm{TMEDA}$ ( 2.2 equiv.) at $78{ }^{\circ} \mathrm{C}$, is stable when allowed to warm to room temperature and does not equilibrate with $\mathbf{1 5}$ in the absence of some other contributor. However, addition of 0.1 equiv. of diisopropylamine to $\mathbf{1 3}$ followed by hydrolysis yields fluorenone $\mathbf{7}$ in $30 \%$ yield.

A mechanism for DreM-cyclization of $\mathbf{1 2}$ was proposed based on experimental data (e.g. isotope labelling) (Scheme 6).[39] It involves an initial amide-base complexation and equilibrium formation of complex $\mathrm{C}$, which reacts fast with an in situ electrophile $\left(\mathrm{Me}_{3} \mathrm{SiCl}\right)$ to afford 14. This rapid reaction prevents equilibration of $\mathbf{1 2}$ with $\mathbf{1 5}$ at temperatures below $-30{ }^{\circ} \mathrm{C}$. Above $30{ }^{\circ} \mathrm{C}$ however, when generated with an amide base, $\mathbf{1 3}$ does undergo undergoes equilibration via $\mathbf{1 2}$ to $\mathbf{1 5}$ (likely formed in traces amount only) which rapidly cyclizes to a stable tetrahedral carbinolamine oxide 16. Upon hydrolysis $\mathbf{1 6}$ affords fluorenone. The fast irreversible nucleophilic cyclization step drives equilibrations towards the formation of fluorenone-precursor $\mathbf{1 6}$ only. The flexibility of the substrate structure, allowing for intramolecular cyclization, is an important feature that permits DreM reactivity. The driving forces for remote metalation of $\mathbf{1 2}$ (ISQ) are potentially significantly different from the ones described for substrate 4 (Schemes 3 and 4). The nature of the base, either reversibly or irreversibly metalating reactants, leads to alterations of mechanisms and reaction condition requirements. 


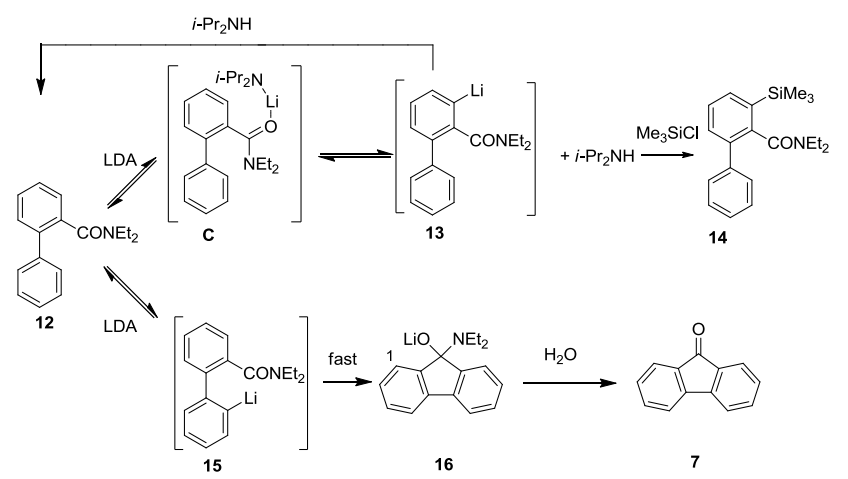

Scheme 6. DreM-nucleophilic cyclization of 2-biphenylcarboxamide (12) with LDA (Snieckus and Mortier, 2010) ${ }^{[36]}$

Strong indirect experimental evidence suggests the carbinolamine oxide $\mathbf{1 6}$ is the stable organometallic species prior to hydrolysis. ${ }^{[36]}$ Corroborative support for carbinol amine intermediates most likely existing as dimers or larger complexed species is inferred by a qualitative IR spectrometric study on DreM of a related biaryl 2-amide (Scheme 7). ${ }^{[43]}$ Treatment of $\mathrm{N}, \mathrm{N}$-diethyl-4-(3-methoxy-phenyl)-nicotinamide 17 with LDA leads to the gradual disappearance of the amide carbonyl stretching frequency $\left(v=1632 \mathrm{~cm}^{-1}\right)$ of the starting amide $\mathbf{1 7}$ as a function of time upon gradual addition of 3 equiv. of LDA. After addition of $\mathrm{MeOH}$, the stretching absorption of the carbonyl $(v=$ $1718 \mathrm{~cm}^{-1}$ ), representing azafluorenone 19, increases in intensity.

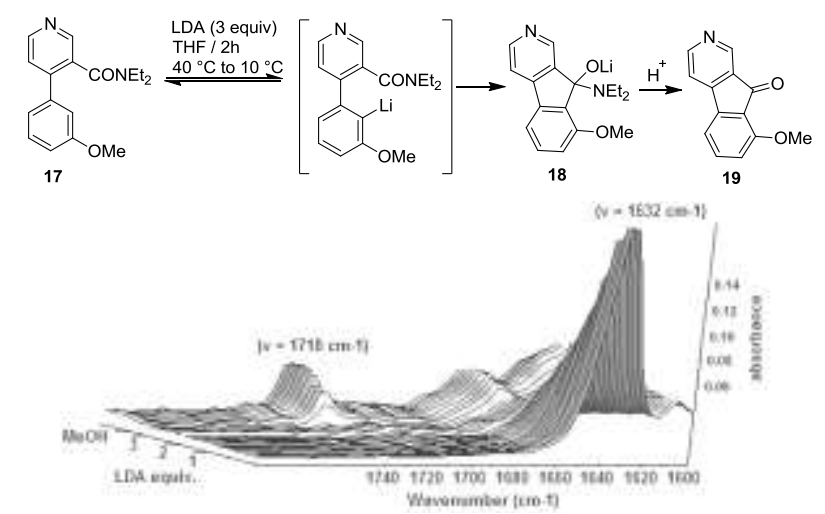

Scheme 7. React IR spectrometric profile of DreM-cyclization of 17 with LDA (Snieckus et al., 2007) ${ }^{[43]}$

\section{Reaction Paramaters for DreM with Intramolecular Quench}

The influence of coordination properties and steric hindrance at the DMG, conformation constraints in the molecule, acidity of hydrogens at positions remote from DMG, and temperature in DreM transformations are discussed below. An analysis of these variables offers guidance for the selection of reaction conditions for optimum DreM efficiencies.

Activating properties of DMG: Various electrophilic DMGs on flexible biaryl substrates are suitable for efficient DreMintramolecular quench sequences. The efficiency of a DMG to promote remote metalation relies on an intimate combination of electrophilic, Lewis basic, and acidifying properties along with suitable the conformation of the molecule.

Strong coordinating properties of a directing group do not guarantee effective remote metalation directing suitability. For example, 2-biphenylcarboxamides and 2-biphenylcarbamates undergo efficient DreM under mild conditions when mixed with
LDA. ${ }^{[23-33]}$ In contrast, 2-biphenyloxazoline fails to metalate at the remote position using LDA with the oxazoline moiety being a good Lewis base but weaker electrophile. The carboxylate group is a better electrophile but weaker Lewis base than the amide group however 2-biphenylcarboxylic acid does not cyclize under LDA conditions. ${ }^{[35 a]}$ Carbamates and amides show better directing group efficiencies towards remote metalation under mild conditions presumably by achieving better remote activation through formation of complexes and long range acidification effects as already observed in DoM. ${ }^{[1-2,3 b]}$

Steric hindrance at the DMG: Steric hindrance at the DMG is detrimental to the efficiency of DreM-intramolecular quench. ${ }^{\text {[22, 44] }}$ Steric hindrance may lead to conformational constraints which cause the coordinating electrophilic DMGs to be distal from the remote position, ${ }^{[44 \mathrm{~b}]}$ thus disfavoring any CIPE and making intramolecular electrophilic quench difficult. To date, a remote anion has yet to be trapped by an external electrophile when intramolecular substitutions are disfavored by steric hindrance. Such observation is consistent with mechanisms where remote metalations at traces amount are followed with intramolecular irreversible rapid quench driving equilibria towards the efficient formation of products.

Conformational constraints: The importance of conformational constraints was highlighted in a synthesis of kinobscurinone, ${ }^{[45]}$ which involved a mixture of two stable atropisomers 20 A/B separable by chromatography (Figure 6). When the isomeric (1:1) $\mathbf{A} / \mathbf{B}$ mixture was treated with LDA (6 equiv.) at room temperature, only A was converted into the cyclized product. Competitive unknown side reaction(s) precluded a more efficient conversion of $\mathbf{B}$ into fluorenone by $\mathbf{A} / \mathbf{B}$ equilibration. At lower temperatures the reaction did not proceed at significant rates while at $45{ }^{\circ} \mathrm{C}$ poor yields $(38 \%)$ of fluorenone were obtained with no recovery of $\mathbf{2 0}$. The authors invoked the CIPE model and cited restricted arylamide bond rotation. The isomer A-LDA complex leads to productive metalation and cyclization while isomer B-complex cannot achieve the transition state for analogous deprotonation. The rate of equilibration of $\mathbf{B}$ or its LDA complex with the equivalent species of isomer $\mathbf{A}$ must then be slow relative to their decomposition pathways, thus precluding higher conversion into the cyclized product.

As an alternative explanation, we propose that a remote anionic species of $\mathrm{B}$, formed in traces amount only, could fail to efficiently cyclize due to conformational constraints, thus depriving the DreM-cyclization process from its in situ quench driving force.

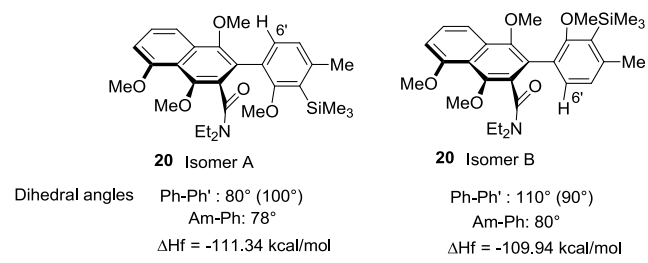

Figure 7. Atropisomers intermediates in the synthesis of kinobscurinone (Snieckus et al., 1997) ${ }^{[45]}$

Acidity of remote hydrogens: The thermodynamic acidities of remote hydrogens influence the regioselectivity of DreM. Remote hydrogens can be acidified via inductive effects and by coordination of metal bases with proximal substituents. ${ }^{[22,46]}$ 
Acidified remote positions are metalated preferentially, affording regioselective transformations often complementary those observed for Friedel-Crafts reactivity. ${ }^{[22-33]}$ Heteroatom bridged arenes, where an atom or a group of atoms $\left(\mathrm{SO}_{2},{ }^{[47]} \mathrm{O},{ }^{[23 \mathrm{i}, 44 \mathrm{a}]}\right.$ $\left.\mathrm{P}(\mathrm{O}) \mathrm{Ar},{ }^{[48]} \mathrm{NR},{ }^{[23 \mathrm{a}, 23 \mathrm{~h}, 44]} \mathrm{CO},{ }^{[49]}\right)$ separates the two aromatic rings, have served as suitable metalation substrates for the synthesis of many heterocyclic structures. ${ }^{[50]}$ To illustrate thermodynamic acidity effects in DreM, 6-chloro-3'-methoxy-2biphenylcarboxylic acid 21 gives 1-methoxy-5-chlorofluoren-9one 22 as the sole product upon treatment with LDA (Scheme 8). ${ }^{[51]}$ In contrast, 6-chloro-2-biphenylcarboxylic acid $\mathbf{2 3}$ does not cyclize under these conditions. A stronger base, LiCKOR, in benzene at $60{ }^{\circ} \mathrm{C}$ is necessary to afford 5-chlorofluoren-9-one 24 (39\%) via metalation at $\mathrm{C} 2$ '.

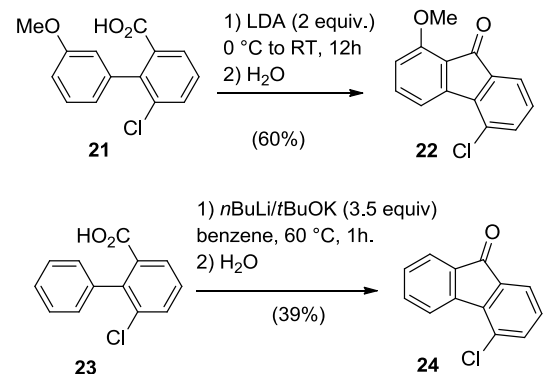

Scheme 8. DreM-cyclization on 6-chloro-2-biphenylcarboxylic acids (Mortier et al., 2008) ${ }^{[50]}$

In Scheme 9, azabiaryls were treated with LDA to form azafluorenones. $^{[43]}$ These products result from metalation on the phenyl ring rather than the more acidic pyridine ring. Small equilibrium concentrations of the lithiated species at $\mathrm{C} 2$ ' and $\mathrm{C} 2$ are generated, the reaction is driven by an irreversible intramolecular nucleophilic cyclization and by the activating effects of remote substituents.
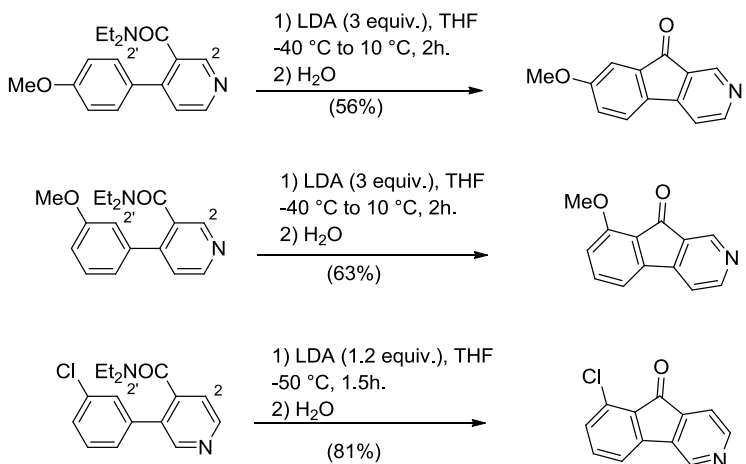

1) LDA ( 1.2 equiv.), THF $-50{ }^{\circ} \mathrm{C}, 1.5 \mathrm{~h}$. 2) $\mathrm{H}_{2} \mathrm{O}$

$$
(81 \%)
$$
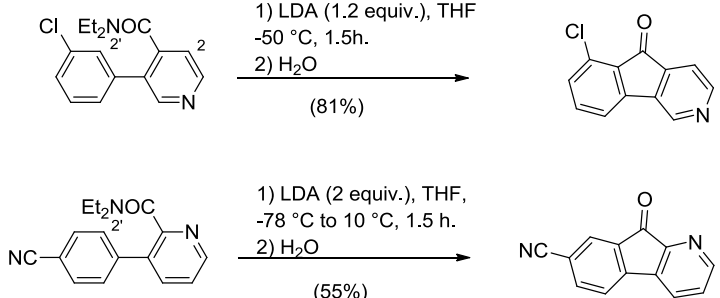

1) LDA (2 equiv.), THF $-78^{\circ} \mathrm{C}$ to $10^{\circ} \mathrm{C}, 1.5 \mathrm{~h}$. 2) $\mathrm{H}_{2} \mathrm{O}$

$(55 \%)$

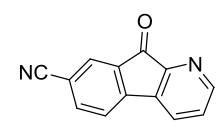

Scheme 9. DreM-cyclization to azafluorenones (Snieckus et al., 2007) ${ }^{[43]}$

The presence of heteroatoms in the substrates offers further opportunities for alternate metalation sites. Lower yields of DreM-nucleophilic cyclization are obtained when substituents cause side reactions and tuning of reaction conditions is required. ${ }^{[47-48]}$

Temperature: Most DreM with intramolecular quench reactions take place at temperatures above $-50{ }^{\circ} \mathrm{C}$. ${ }^{[20-33,35-36,44,52]}$ So far, attempts to trap remote anions at lower temperatures have failed with starting materials recovered. This observation is of mechanistic significance as lower temperatures do not allow for a fast intramolecular irreversible nucleophilic quench and therefore DreM does not happen at low temperatures $\left(\sim-78{ }^{\circ} \mathrm{C}\right)$. DreMannulations directed by amide or ester groups are efficiently achieved at temperatures above $-30{ }^{\circ} \mathrm{C}$ when electrophilic substitutions become efficient. Some DreM-anionic remote Fries rearrangements even require heating. ${ }^{[25,45,47-48,53]}$

The studies on metalation of $N, N$-diisopropyl-2-(4-chloro-2pyridyl)benzamide 25 and derivatives (Scheme 10) highlight the influence of temperature on the kinetics of nucleophilic cyclization. ${ }^{[54]}$ At $-75{ }^{\circ} \mathrm{C}$, LTMP in THF promotes the regioselective metalation of 25 at $\mathrm{C} 5$ ' only. This is a position far from the carbonyl function but proximal to the chlorine substituent. Deuterium incorporation occurs quantitatively at $\mathrm{C} 5^{\text {‘ }}$ only. Despite strong coordinating ability of the carbonyl DMG, the metalation is directed by the chlorine substituent which acidifies the hydrogens at $\mathrm{C} 3$ ' and $\mathrm{C} 5$ ' of $\mathbf{2 5}$ and exerts a stabilizing effect on the corresponding lithio-derivative. Position $\mathrm{C}^{2}$, was determined to have the more acidic hydrogen by molecular simulations. Steric hindrance to metalate C3' position was also invoked to account for the observed regioselectivity. When the reaction is warmed up, equilibrations between $\mathrm{C} 3$ ' and $\mathrm{C} 5$ ' lithiated pyridines $\mathbf{2 8}$ and $\mathbf{2 9}$ are shifted towards the 3'-lithiated ($50{ }^{\circ} \mathrm{C}$ ). The amide group acts as an irreversible in situ trap for the 3 '-lithiated pyridine to form the respective azafluorenone 27 along with $\mathrm{C} 5^{\prime}$ deuterated product after deuteriolysis. Through thermodynamic control, the carbonyl group irreversibly traps the metalated species at $\mathrm{C} 3$ ' which shifts equilibrium towards the formation of cyclized product 27.

The reaction mechanism of this transformation is significantly different from the one described for the biphenyl-2-carboxylic acid and carboxamide described earlier (see Schemes 3-6). We propose the terminology "Directed isomerization of preformed remote anions" to describe these transformation where the initial metalation is independent from any remote unit.

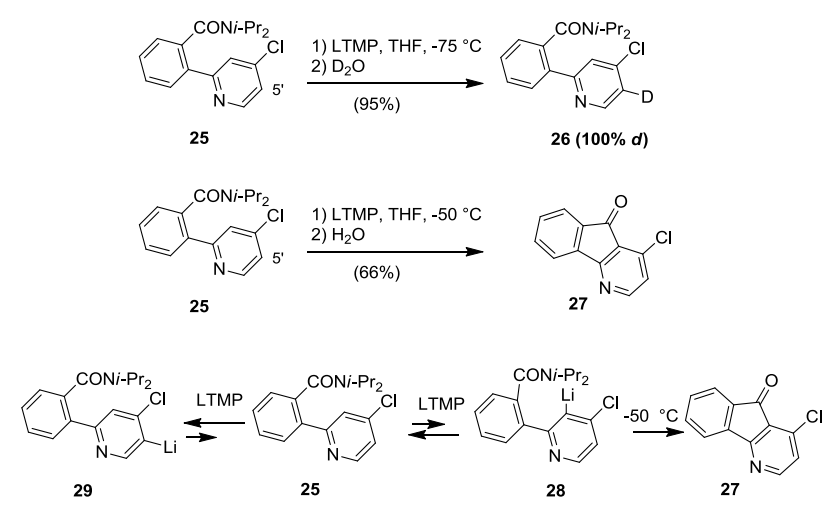

Scheme 10. Directed isomerization of remote anion 29 (Mongin et al., 2004) ${ }^{[54]}$

\section{Migrating DMG: Remote Anionic Fries Rearrangement}

Electrophilic DMG with migrating abilities can translocate onto metalated sites thereby reacting via remote anionic Fries rearrangements (Scheme 11). ${ }^{[25,45,47-48,53]}$ On carbamate 2substituted biaryl structures, carbamoyl units migrate to the 
kinetically favored metalation sites. The ortho positions systematically need protection to enable remote anionic Fries rearrangement. Remote metalation of these structures with lithium amides follows an unfavorable equilibrium with the $\mathrm{pKa}$ of amide bases often being lower than $\mathrm{pKa}$ of remote hydrogens. Attempts to trap remote anions $\mathbf{3 0}$ with external electrophiles have failed. A lack of measurable build-up of remote anionic species indicates a rate-limiting remote metalation followed by a rapid Fries rearrangement. The irreversible carbamoyl translocation onto a remote anionic position likely drives the lithiation equilibrium towards the rearranged Fries product $\mathbf{3 1}$ following Le Châtelier's principle. ${ }^{[53,55]}$ Additional activation of the remote position with proximal substituents proves beneficial for control of the regioselectivity of metalation. Tandem remote anionic Fries followed by anionic Friedel-Crafts acylation were reported as a one-pot process to form compounds 32. ${ }^{[23 b, 23 f, 26]}$ DreM-DMG translocation sequence was used in concert with $\mathrm{D} o \mathrm{M}$ and cross coupling chemistry to synthesize dibenzopyranones, ${ }^{\text {23c, } 23 \mathrm{i}, 30,53 \mathrm{a}]}$ defucogilvocarcin V[27], ${ }^{[26]}$ and plicadin. ${ }^{[29]}$ Treatment of $\mathrm{N}$ carbamoylindoles 34 with LDA provided a general route to functionalized 2-arylindoles, benzo[a]carbazoles and indeno[1,2b]indoles. ${ }^{[48]}$
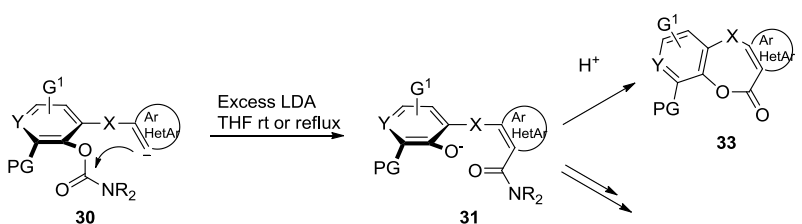

$P G=O M e, \mathrm{Et}_{3} \mathrm{Si}, \mathrm{Me}_{3} \mathrm{Si}$

$\mathrm{Y}=$ none or $\mathrm{C}, \mathrm{O}, \mathrm{N}, \mathrm{S}$ at different positions on the rings

$\mathrm{G}^{1}=$ various substituents

$\mathrm{X}=\mathrm{P}(\mathrm{O}) \mathrm{R}, \mathrm{SO}_{2}$
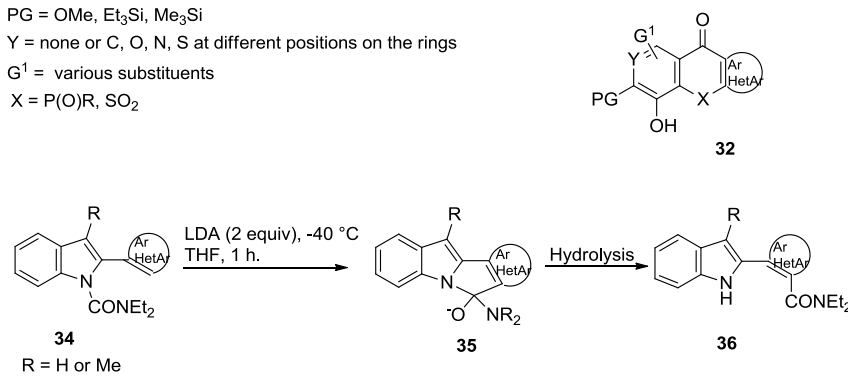

Scheme 11. Remote Anionic Fries rearrangement (Snieckus et al., 1994, 2008) ${ }^{[53]}$

\section{Remote Tolyl Groups: Remote Lateral Metalations- Nucleophilic Cyclizations}

Directed remote lateral metalations with nucleophilic cyclizations are reported to occur on flexible biaryl substrates bearing tolyl groups at position remote from electrophilic DMG. An early example was reported by Fouche and Leger: $N$-alkyl- $N$ - $(o-$ tolyl)anthranilic esters 37 react with lithium diethylamide to form dihydro-10,11-dibenzo[b,f]azepines 38 (Scheme 12). ${ }^{[52]}$ Directed remote lateral metalation and annulation was later described for various systems using oximes ethers, hydrazones, nitriles, amides as directing groups, ${ }^{[27]}$ and were successfully applied to the synthesis of 9-aminophenanthrenes, ${ }^{[27,}$ 31] 9 -phenanthrols, ${ }^{[56]}$ antiepileptic drug trileptal, ${ }^{[44 b]}$ eupolauramine[31], ${ }^{[30]} \beta-$ lapachone, ${ }^{[28]}$ among other examples. ${ }^{[23 g, 32,53 \mathrm{a}]}$ The pKa of amide bases is lower than pKa of 4-methylbiphenyl methyl hydrogen
(>40.2). ${ }^{[57]}$ Metalation of the remote lateral position was initially explained through CIPE, and is likely favored by ISQ. ${ }^{[58]}$

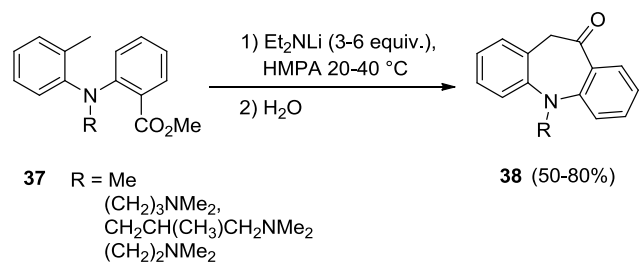

Scheme 12. Directed lateral metalation-nucleophilic cyclizations on $N$-bridged biarylic structures (Fouche and Leger, 1972) ${ }^{[52]}$

When competition between remote aromatic metalation and remote lateral metalation is possible (Scheme 13), the outcome is difficult to predict. ${ }^{[44]}$

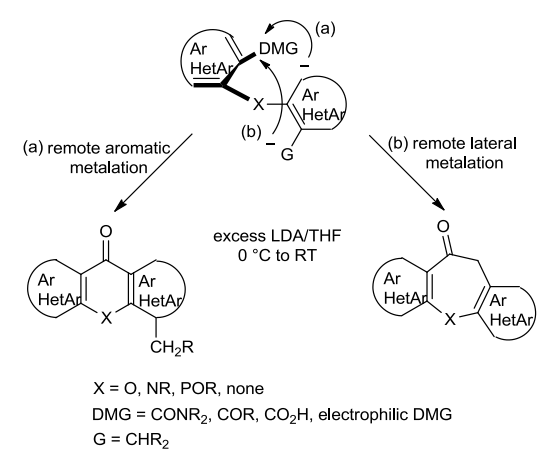

Scheme 13. Competition between remote aromatic metalation-nucleophilic cyclization and remote lateral metalation-nucleophilic cyclization.

Diarylamides substituted at position 2 by electrophilic DMGs usually undergo lateral remote metalation-cyclization reactions in the presence of lithium bases to form dibenzoazepinones. For example, treatment of diarylamides $\mathbf{3 9}, \mathbf{4 0}$ and $\mathbf{4 1}$ with 2-4 equiv. of LDA in THF at $0{ }^{\circ} \mathrm{C}$ yields dibenzoazepinone $\mathbf{4 2}$ preferentially with good selectivities (Scheme 14). The selectivity depends on the steric hindrance at the DMG. The activation of the remote aromatic ring position with proximal substituents $(\mathrm{OMe}, \mathrm{Cl})$ can sometimes allow a remote ring metalation-cyclization process to compete to give acridones. In such cases, tuning of reaction conditions is necessary to achieve selective transformations. ${ }^{[24,44 a]}$

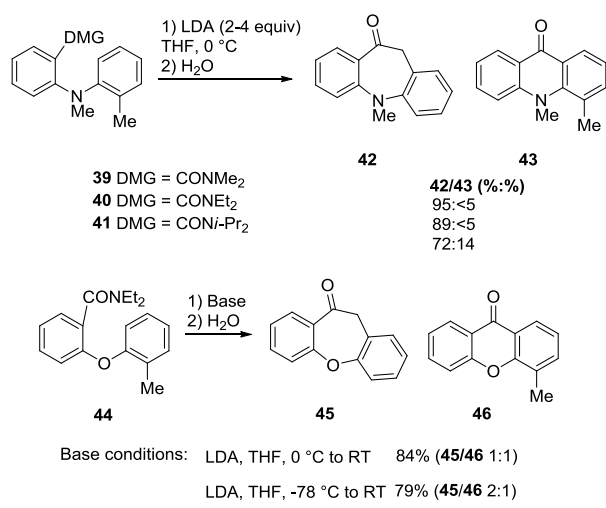

Scheme 14. Directed Lateral remote metalation on $N^{[23 \mathrm{~h}, 44 \mathrm{a}, 52]}$ and $O$-bridged ${ }^{[24,44 a]}$ biarylamides (Snieckus et al. 1997, 2008) 
In contrast to the good regioselectivity observed for product formation in the dibenzo[b,f]azepinone series, LDA-mediated cyclization of diphenyl ether $\mathbf{4 4}$ resulted in a reproducible equimolar mixture of dibenzo[ $b, f]$ oxepinone $\mathbf{4 5}$ and xanthone $\mathbf{4 6}$ $\left(0{ }^{\circ} \mathrm{C}\right.$ to $\mathrm{rt}$, Scheme 14$)$. Treatment of $\mathbf{4 4}$ with LDA at $-78{ }^{\circ} \mathrm{C}$ followed by warming to room temperature showed some selectivity for formation of dibenzo[ $b, f]$ oxepinones $(45 / 46 \approx 2)$. The oxygen bridge of diarylether $\mathbf{4 4}$ inductively activates remote ring positions. ${ }^{[59]}$ Reduced temperatures are required in order to achieve lateral metalation on such reactants. Aromatic ring metalations are favored over lateral metalation through a collaborative effect of a second proximal activating group. ${ }^{[24,44 a]}$

To gain insights into the driving forces for those transformations, DFT calculations were used to help rationalize the selectivities of formation of cyclized products by remote lateral metalation-nucleophilic cyclization for substrates $\mathbf{4 0}$ and 44. ${ }^{[44 a]}$ The lateral metalation products, $\mathbf{4 2}$ and $\mathbf{4 5}$, were calculated to be thermodynamically unfavourable as these were less stable than $\mathbf{4 3}$ and 46. The significance of other results obtained by DFT calculations of low energy conformation of intermediate structures leading to the cyclized products was unclear. The data seemed to indicate that the rate constant of cyclization would likely supersede conformation criteria during the reactions.

\section{Optional Site Selectivity in DreM}

When different regioisomers of a product can be formed, the choice of DMG is critical for regioselective reactivity. For some systems, it has been possible to switch regioselectivities of remote metalation by changing DMGs.

2-(Pyridin-2-yl) and 2-(pyridin-4-yl) benzoic acids 47 and 49 afford azafluorenones $5 \mathrm{H}$-indeno[1,2-b]pyridin-5-one 48 and $9 \mathrm{H}-$ indeno[2,1-c]-pyridin-9-one 50 by treatment with LDA or LTMP in THF at RT (Scheme 15). ${ }^{[60]}$ The formation of azafluorenones likely follows a mechanism similar to DreM of 2biphenylcarboxamide 12 (see Scheme 6). ${ }^{[36]}$

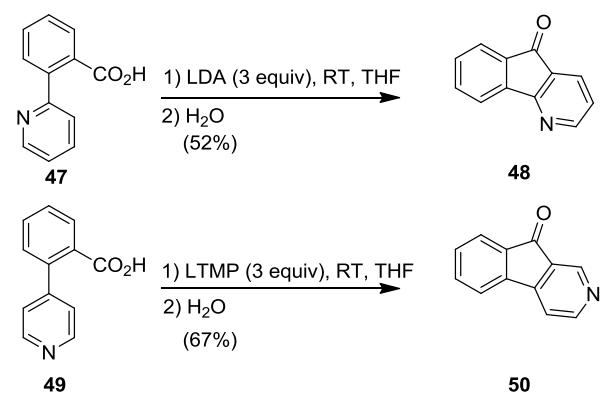

Scheme 15. DreM-cyclization on 2-(pyridin-2-yl) and 2-(pyridin-4-yl) benzoic acids 47 and 49 (Mongin et al., 2003) ${ }^{[60]}$

A dramatic change of regioselectivity occurs during the DreM-cyclization of 2-(pyridin-3-yl)benzoic acid derivatives 51ac with lithium bases. Formation of either of the two azafluorenone isomers with complete regiocontrol can be achieved by altering the choice of DMG (Scheme 16). ${ }^{[35 b]}$

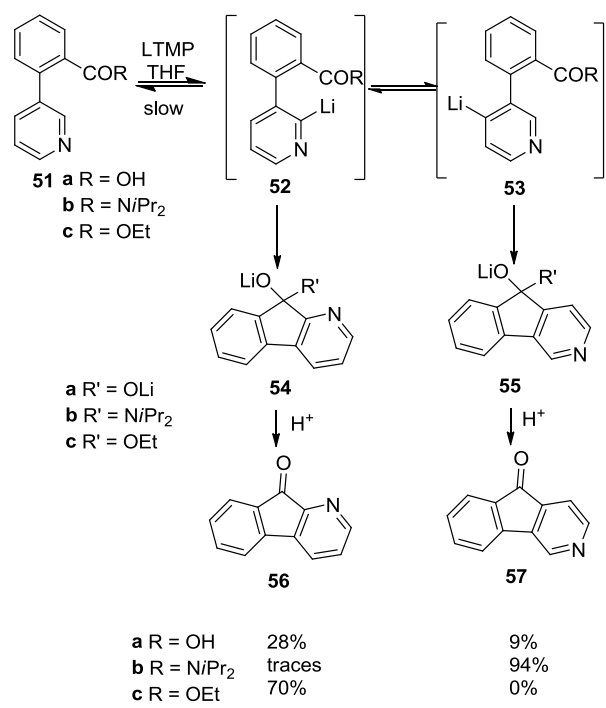

Scheme 16. DreM-cyclization of 2-(pyridin-3-yl)benzoic acid derivatives 51a-c (Mortier et al., 2006) ${ }^{[35 b]}$

In 2-(pyridin-3-yl)benzoic acid derivatives 51a-c, the pyridine nitrogen pyridine and Lewis basic DMG compete for coordination with the lithium base. The DMG and the pyridine nitrogen are too far apart to ensure double complexation with the base. ${ }^{[61]}$ As the DMG changes from $\mathrm{CO}_{2} \mathrm{Et}$ to $\mathrm{CO}_{2} \mathrm{Li}$ and $\mathrm{CONEt}_{2}$, the coordinating properties of the DMG are altered. This potentially modifies the preferential coordination site for lithium bases and also affects the activation of remote hydrogens through both complexation and electronic effects. Ester-LDA complexes are

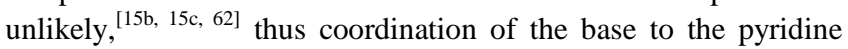
nitrogen is likely for 2-(pyridin-3-yl)benzoic ester 51c. The preferential coordination site for the two other reactants is unclear. In each case, the carbonyl derived DMG is expected to direct metalations at ortho position and/or at $\mathrm{C} 2$ ' and C4'. Potential cumulative effects of nitrogen and carbonyl directing groups may explain metalations of remote positions. Importantly, the DMGs have varying electrophilicity. Thus switching DMGs strongly affects the kinetics of the critical step of nucleophilic cyclization.

When DMG is $\mathrm{CO}_{2} \mathrm{Et}$ (strong electrophile, 51c), complexation of the base with the nitrogen of the pyridine likely directs the formation of the kinetic anion 52c which is destabilized by electronic repulsion between the carbanion and the lone-pair of the azine nitrogen. Species 52c does not have a long-enough lifetime to isomerize to the thermodynamically more stable (less basic) 4'pyridyllithium 53c and therefore cyclizes rapidly to give monolithium salt $\mathbf{5 4 c}$ leading to azafluorenone $\mathbf{5 6}$ as a sole product after hydrolysis.

$\mathrm{CON} i-\mathrm{Pr}_{2}$, a stronger Lewis base, competes with the pyridine nitrogen for coordination. It also is a weak electrophile in comparison to an ester. The azafluorenone $\mathbf{5 7}$ is obtained with complete regiocontrol and high yield. Isomerization of a potentially formed kinetic C2' pyridine anion 52b to a more thermodynamically stable $\mathrm{C} 4$ ' anion 53b may take place before cyclization (kinetically slower cyclization). Complexation of the base to the amide followed by metalation at the most acidic remote hydrogen position is also possible. ${ }^{[63]}$ Carboxylate 51a displays a reactivity pattern intermediate between the two previous limiting cases. From compound 51a, both azafluorenones 56 and $\mathbf{5 7}$ are formed. Cyclizations of the remote carbanions $\mathbf{5 2}$ and $\mathbf{5 3}$ give cyclic salts $\mathbf{5 4}$ and $\mathbf{5 5}$ that are more thermodynamically stable than an ortho carbanion. 
DreM followed by nucleophilic cyclizations of benzoic acid derivatives $\mathbf{5 1}$ are dictated through a combination of factors such as: the acidity of the remote hydrogens, the ability of the directing group to interact with the lithium base towards the formation of a favorable low-energy transition state, activating remote metalation, electrophilicity of DMG, and thermodynamic versus kinetic considerations. None of these parameters should be considered independently. Notably, no DreM is observed when carbonyl derived directing groups are replaced by non-electrophilic OMe units on structures 47, 49 and 51 (Scheme 17). DoM at the anisole ring and/or at the pyridine ring occurs on $\mathbf{5 8}$ without further isomerization. ${ }^{[64]}$

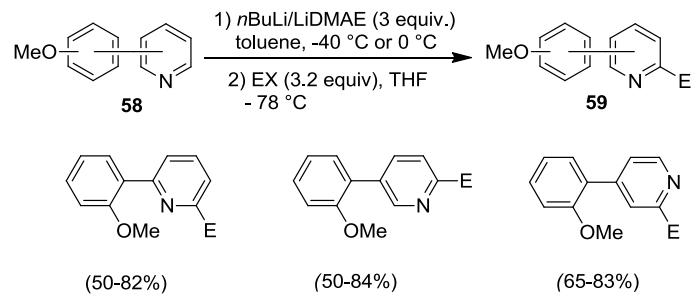

$\mathrm{E}=\mathrm{D}, \mathrm{Cl}, \mathrm{Br}, \mathrm{I}, \mathrm{SMe}, \mathrm{PPh}_{2}, \mathrm{COPh}, \mathrm{CH}(\mathrm{OH}) \mathrm{Ph}, \mathrm{MeCH}(\mathrm{OH}) \mathrm{Et}$

Scheme 17. Lithiation of anisylpyridines (Fort et al., 2005) ${ }^{[64]}$

\section{DreM with Quench by External Electrophiles}

Quench of remote anions with external electrophiles has been reported for non-electrophilic coordinating DMG, and for structurally rigid substrates that do not allow for intramolecular quench by remote electrophilic non-migrating DMGs (Figure 2, C and D). Few examples of quench of anions remote from DMGs using external electrophiles are reported. Presumably, hydrogens at positions remote from DMGs are less activated through inductive effects and any driving force brought by intramolecular quench of remote anion with electrophilic DMGs (ISQ technique) is absent, thus making abstraction of remote hydrogens challenging. This is in accordance with a nucleophilic cyclization step being a significant driving force in some DreMintramolecular quench sequences. The use of alkyl lithium bases that favour the formation of clusters is the norm for DreM using non-electrophilic DMGs. To date, no mild conditions (i.e. $-78{ }^{\circ} \mathrm{C}$ ) have been reported to generate remote anions quenchable by external electrophiles. The following sections unravel the mechanisms and driving forces of DreM followed by quench with external electrophiles.

\section{DreM on Rigid Substrates with Electrophilic Non-Migrating DMG}

When electrophilic coordinating and non-migrating DMGs are present on rigid substrates, the lack of flexibility does not allow for intramolecular quench of remote anions by DMG. In such cases, quench by external electrophiles of remote metalated species becomes possible.

Regioselective directed metalation of dibenzodioxin-1carboxylic acid $\mathbf{6 0}$ at the $\mathrm{C} 9$ position was achieved by treatment of $t$-butyllithium (2 equiv. at $-78{ }^{\circ} \mathrm{C}$, Scheme 18). ${ }^{[65]}$ Trapping of the metalated species with various electrophiles afforded good yields of 9-substituted products $\mathbf{6 1}$ only. Amide bases were not effective in these transformations. Dibenzodioxin itself is not metalated at $78^{\circ} \mathrm{C}$. Activation and remote direction of metalation at $\mathrm{C} 9$ by the initially formed $\mathrm{ArCO}_{2} \mathrm{Li}$ group was confirmed with experimental evidence.

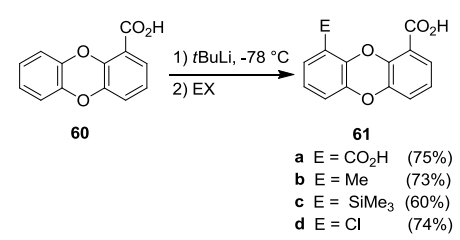

Scheme 18. DreM of dibenzodioxin-1-carboxylic acid 60 (Palmer et al., 1990) ${ }^{[65]}$

Remote metalation from a carboxylate unit was also observed on the related phenoxathiin ring system $\mathbf{6 2}$ by treatment with $t$ butyllithium at $-78^{\circ} \mathrm{C}$ (Scheme 19). ${ }^{[65]}$ Under the same reaction conditions, the isomeric 1-carboxylic acid $\mathbf{6 4}$ failed to react yielding only recovered starting material, presumably due to the reduced ability of sulphur compared with oxygen to activate its ortho position. Mechanistically, both the inductive acidifying effect of the oxygen bridge and the anchoring effect of the carboxylate group work in concert to bring about the regiospecific remote metalation.

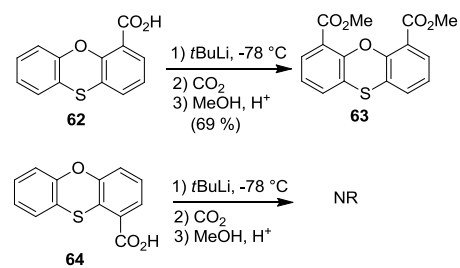

Scheme 19. Lithiations of phenoxathiin-4-carboxylic acid $\mathbf{6 2}$ and phenoxathiin-1carboxylic acid 64 (Palmer et al., 1990) ${ }^{[65]}$

\section{Can Addition of External Electrophiles Initiate Remote Metalation?}

Much is known about the structures of lithium alkyls and amides but less is known about how they react and the nature of the lithiated species produced prior to workup of metalations. In the case of directed metalation, lithiated species are usually not characterized directly because of their high reactivity and instability and their expected aggregation and solvation making direct analysis complicated. Anions from metalation are trapped with electrophiles and the efficiency of formation of quenched products is used as indirect evidence to extrapolate prior efficiency of regioselective metalation. Such interpretation can sometimes be sometimes misleading. For example, it does not apply to reactions using ISQ techniques, where high yields of substituted products are obtained even though only trace amounts of metalation occur.

The reaction of dibenzodioxin 65 at $-30{ }^{\circ} \mathrm{C}$ with $t$-butyllithium ( 2 equiv.) followed by quench with $\mathrm{CO}_{2}$ and esterification gives the 1,9-diester from 61a (69\%). This suggests that a 1,9-dianion might be generated (Scheme 20). ${ }^{[65]}$ However, when quenched with iodomethane or dimethylformamide, only 1-substituted dibenzodioxins 68 are isolated, indicating that at this temperature only monometalation occurs to any appreciable extent. Apparently, in the special case of quenching with $\mathrm{CO}_{2}$ the initially formed 1-carboxylate salt is able to direct a subsequent remote metalation at the 9-position during the quench. Mechanistically, the kinetics of competitive reactions between the electrophiles and 
the metalated species and mixed aggregates during the addition could lead to formation of the DreM products. The electrophile could have faster reaction kinetics with mixed aggregates than with $n \mathrm{BuLi}$ in solution. Thus, remote metalation would be initiated by addition of the electrophile. Analogous metalations initiated by addition of electrophiles were reported on other structures. ${ }^{[66]}$
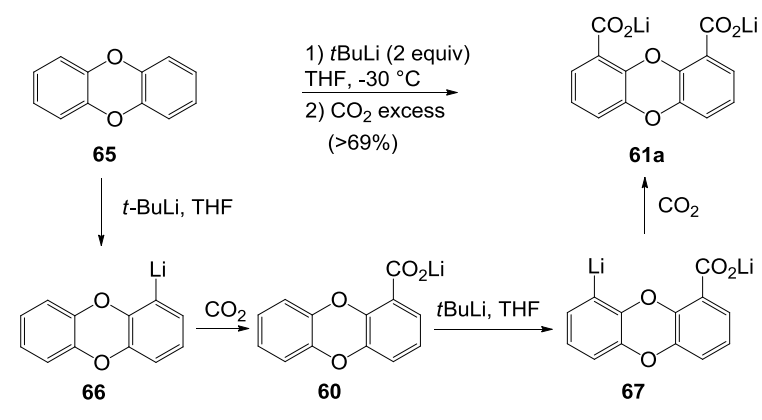

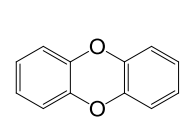

65
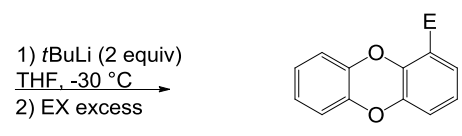

68 a $E X=M e l \quad E=M e \quad(80 \%)$ b $E X=D M F \quad E=C H O(84 \%)$

Scheme 20. Electrophile mediated metalation of dibenzodioxin (65) with $t$ BuLi. (Palmer et al., 1990) ${ }^{[65]}$

\section{DreM with a Non-Electrophilic Amino DMG}

DreM of biarylamines assisted by an amino group were first reported in the 1960s (Scheme 21). ${ }^{[19]}$ In the presence of 4.5 equivalents of $n$-butyllithium at room temperature in diethylether, metalations of 2-aminobiphenyls 69 at $\mathrm{C} 2$ ' on the phenyl ring followed by quench with dimethylformamide or carbon dioxide led to the formation of cyclic products in moderate yields. ${ }^{[19]}$ This methodology was applied to the synthesis of phenanthridines $\mathbf{7 1}$ and phenanthridones 72. The syntheses of dibenzo $[b, f][1,4]$ oxazepine $\mathbf{7 5 a}$ and dibenzo $[b, f][1,4]$ thiazepine 75b were described with $C, N$-dilithiation of 2-biarylamines being the key step. Notably when $\mathrm{X}=\mathrm{NH}, 1$-phenylbenzimidazole $\mathbf{7 6}$ was formed by $N$-formylation instead of $C$-formylation. ${ }^{[67]}$ Recent improvements have been made in the metalation of metalate substrates $\mathbf{7 3}$ at remote positions using 2 equivalents of $n$ butyllithium/TMEDA in hexane (Scheme 21). ${ }^{[68]}$ Under such conditions, lithiation of 2-amino diphenylether 73a proceeds rapidly with high regioselectivity. Upon quenching with excess iodomethane, $C, N$-dimethylated product 78a is formed in $93 \%$ yield (Scheme 21). ${ }^{[68 \mathrm{a}]}$ Similarly, the di-lithiation of $o$-amino diphenylsulfone 73d in THF affords the $C, N$-dimethylated product 78b. Other examples include the formation of 11-pyridyldibenzo[b,f][1,4] oxazepines 77a, 11-(3-dimethylaminopropyl)-and dibenzo $[b, f][1,4]$ oxazepines $\quad \mathbf{7 7 b}, \mathbf{c} .{ }^{[68 b]}$ The $\quad C, N$-dilithio intermediate $\mathbf{7 4}$ from o-amino diphenylsulfone affords the tricyclic structure 77c after quench with methyl cyclopropanecarboxylate. Mechanistically, CIPE and an increased thermodynamic acidity of remote aromatic hydrogens for bridged arenes likely assist these metalations.
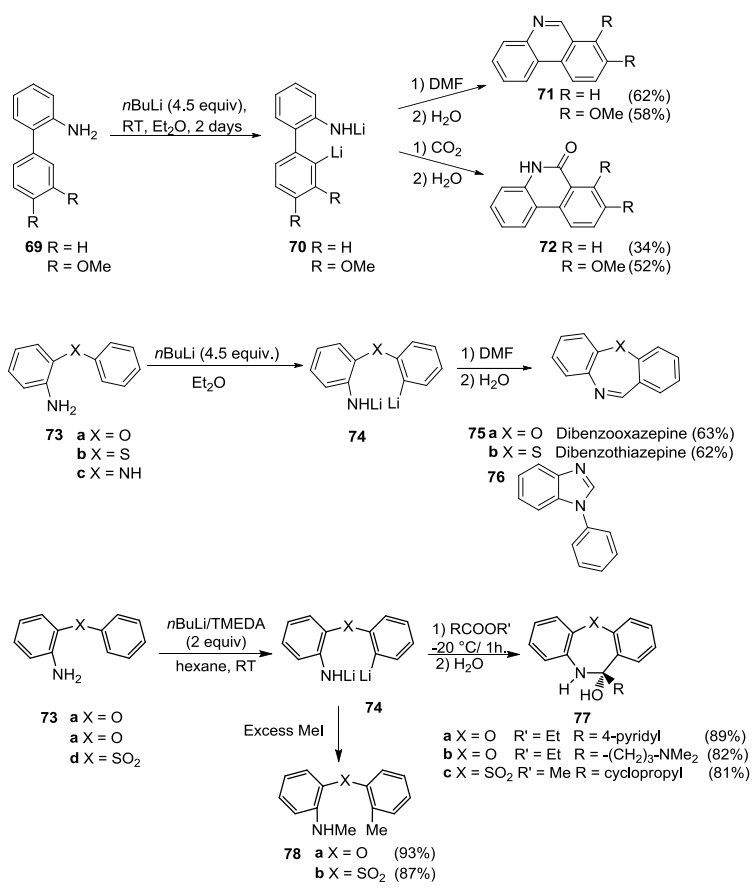

Scheme 21. DreM of 2-aminobiaryl structures (Narasimhan et al., 1969, 1975, 1981) ${ }^{[19,67]}$ (Ogle et al., 1997, 1998) ${ }^{[68]}$

Further mechanistic insights to account for DreM directed by the amino group were obtained by a combination of NMR and Xray analyses. ${ }^{[69]} N, N$-dilithiobiphenylamine crystallizes as a cluster containing five $\mathrm{RNLi}_{2}$ units and NMR studies show aggregations in solution. Alkyllithium bases, prone to forming clusters, are necessary to achieve DreM. Milder conditions using lithium amides proved inefficient to metalate remote positions remote. Coordination of an alkyl lithium to the amino anchor acting as ligand may preclude a subsequent remote metalation analogously to the manner in which an amino group directs exclusive perilithiation on 1-aminonaphtalene and on various dibenzophenothiazines with no trace of ortho metalation. ${ }^{[7]}$ The regioselectivity of metalation may be linked to the thermodynamic stability of the anions and aggregates formed. ${ }^{[70]}$

\section{Isomerization of Preformed Anions Controlled by Remote Non Electrophilic Substituents}

Isomerization of preformed anionic species assisted by a Lewis basic remote unit is included under DreM terminology. A substituent directs the isomerization of a preformed carbanion by stabilizing one of the remote metalated isomers through complexation. The DMG does not cause the initial lithiation. We propose the terminology: "directed isomerization of remote anion", to describe this type of transformation. This reactivity was observed with 2,2-dimethyl- $N$-pyridylphenylpropanamides (Schemes 22 and 23). ${ }^{[71]}$ Lithiation of 2,2-dimethyl- $N$-[2-(2pyridyl)phenyl]propanamide $\mathbf{7 9}$ occurs at C6' with in situ quench by LTMP/SiMe ${ }_{3} \mathrm{Cl}$ (Scheme 22). Complexation of the lithium base to the pyridine nitrogen most likely favors a kinetic mechanism over an acid-base mechanism which would promote the abstraction of the most acidic H4' hydrogen. ${ }^{[71]}$ When lithiation of 79 with LTMP was quenched with a deuterium source at room temperature, a mixture of deuterated isomers 81, 82, 83 was observed. Under reversible lithiation conditions, isomerization of the initially-formed 6-lithiopyridine to more stable derivatives at C3' (stabilization through complexation of the metal with the DMG at remote position) and at $\mathrm{C}^{\prime}$ ' or $\mathrm{C} 5$ ' 
(reduction of electronic repulsion between the carbanion and the lone pair of the azine nitrogen) was observed.

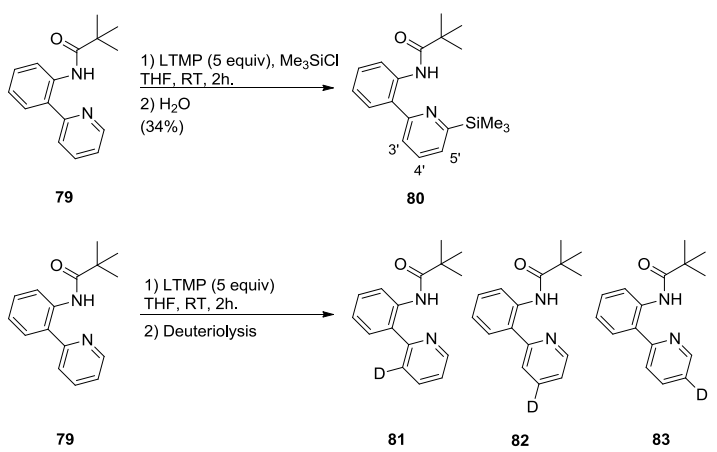

Scheme 22. Metalation of of 2,2-dimethyl- $N$-[2-(2-pyridyl)phenyl]propanamide (79) (Queguiner et al., 2003) $)^{[71]}$

Directed remote isomerization is more apparent on 2,2dimethyl- $N$-[2-(3-pyridyl)phenyl]propanamide 84 (Scheme 23). Metalation occurs at $\mathrm{C}^{\prime}$ ' and $\mathrm{C}^{\prime}$ ' using in situ quenching with LTMP/Me 3 SiCl $(\mathbf{8 5} / \mathbf{8 6}, 66: 34)$. Complexation of the lithium to the pyridine nitrogen probably favors a kinetic mechanism. When deuteriolysis was conducted after 2 hours at $0{ }^{\circ} \mathrm{C}$, only deuterated product at $\mathrm{C} 4$ ' was isolated $(\mathbf{8 7}, 50 \%$ deuterium incorporation, $70 \%$ yield). Under thermodynamic control using reversible lithiation conditions, isomerization of the initially formed lithiopyridines $\mathbf{8 8}$ and $\mathbf{9 1}$ to the more stable derivative $\mathbf{9 0}$ (stabilization through complexation of the metal with the remote DMG) through a series of equilibria is observed.

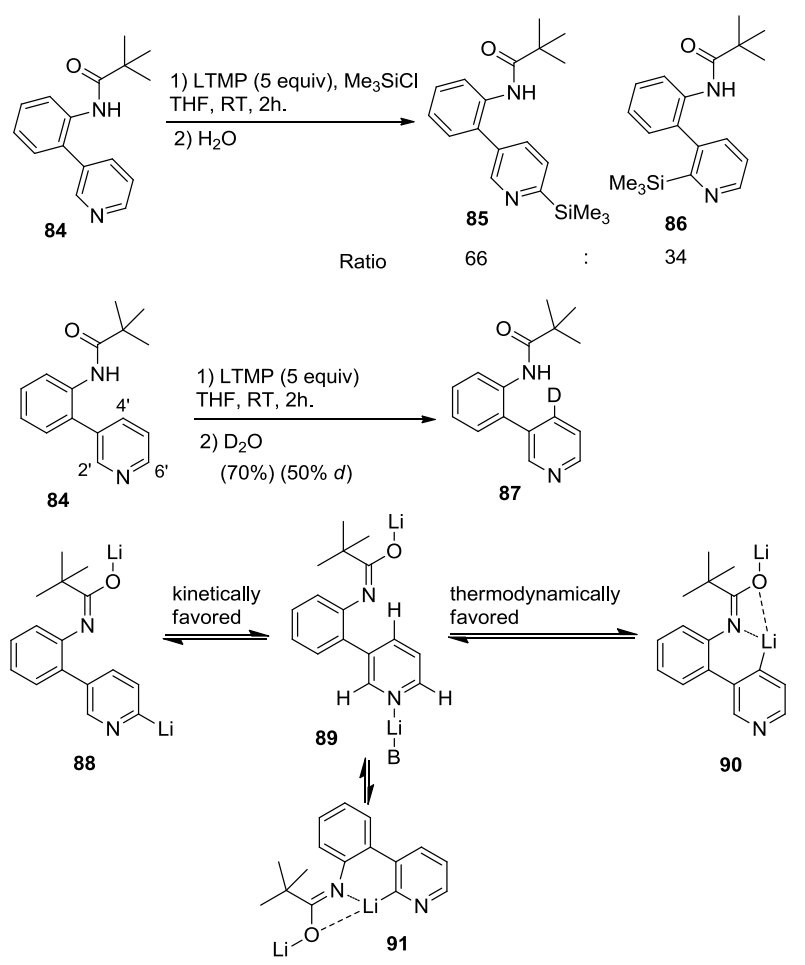

Scheme 23. Metalations of 2,2-dimethyl- $N$-[2-(3-pyridyl)phenyl]propanamide (84) (Queguiner et al., 2003) ${ }^{[71]}$

\section{Summary and Outlook}

The synthetic utility of directed remote aromatic metalation (DreM) is an outcome of good reaction yields and unique reactivity that can be complementarity to Friedel-Crafts transformations. The increasingly widespread use of DreM is, in large part, a result of extensive development efforts in the Snieckus laboratory. CIPE can be considered a useful predicative model but, given the examples presented above, it should not be considered a complete and systematic explanation for directed metalation reactivity without additional mechanistic investigation. Detailed mechanistic studies of organolithium reactions as discussed in this review can contribute to identify potentiallymisleading models for rationalizing regioselectivity and product distributions. Further insight into DreM mechanisms with increased accuracy will continue allow for new regioselective and efficient syntheses. Continued development and will enable a foundation for intelligent design of new transformations just as the $\mathrm{D} o \mathrm{M}$ methodology did for $\mathrm{C}-\mathrm{H}$ bond activations using transition metals. ${ }^{[72]}$

[1] H. W. Gschwend, H. R. Rodriguez, Org. React. 1979, 26, 1.

[2] a) V. Snieckus, Chem. Rev. 1990, 90, 879-933; b) M. C. Whisler, S. MacNeil, V. Snieckus, P. Beak, Angew. Chem. Int. Ed. 2004, 43, 2206-2225.

[3] a) P. Beak, A. Basu, D. J. Gallagher, Y. S. Park, S. Thayumanavan, Acc Chem. Res. 1996, 29, 552-560; b) P. Beak, A. I. Meyers, Acc. Chem. Res. 1986, 19, 356-363

[4] a) M. Schlosser, Organometallics in Synthesis: A Manual, Wiley, Chichester, 1994; b) M. Schlosser, Angew. Chem. Int. Ed. 2005, 44, 376-393.

[5] J. Clayden, Organolithiums: Selectivity for Synthesis, Pergamon, Oxford, 2002.

[6] T. Klis, S. Lulinski, J. Serwatowski, Curr. Org. Chem. 2008, 12, 1479-1501.

[7] a) J. Clayden, C. S. Frampton, C. McCarthy, N. Westlund, Tetrahedron 1999, 55, 14161-14184; b) R. A. Barnes, L. J. Nehmsmann, J. Org. Chem. 1962, 27 , 1939-1942; c) A. J. Kirby, J. M. Percy, Tetrahedron 1988, 44, 6903-6910.

[8] G. W. Gribble, in Name Reactions for Homologations (Ed.: J. J. Li), John Wiley \& Sons, Hoboken, N.J., 2009, pp. 749-764

[9] a) T. H. Nguyen, N. T. T. Chau, A. S. Castanet, K. P. P. Nguyen, J. Mortier, Org. Lett. 2005, 7, 2445-2448; b) D. R. Anderson, N. C. Faibish, P. Beak, J. Am. Chem. Soc. 1999, 121, 7553-7558.

[10] a) D. J. Gallagher, H. Du, S. A. Long, P. Beak, J. Am. Chem. Soc. 1996, 118 , 11391-11398; b) A. Streitwieser, J. E. Williams, S. Alexandratos, J. M. Mckelvey, J. Am. Chem. Soc. 1976, 98, 4778-4784.

[11] a) D. J. Gallagher, P. Beak, J. Org. Chem. 1995, 60, 7092-7093; b) H. Luitjes, F. J. J. Dekanter, M. Schakel, R. F. Schmitz, G. W. Klumpp, J. Am. Chem. Soc. 1995, 117, 4179-4180; c) D. J. Pippel, G. A. Weisenburger, N. C. Faibish, P. Beak, J. Am. Chem. Soc. 2001, 123, 4919-4927; d) S. T. Chadwick, R. A. Rennels, J. L. Rutherford, D. B. Collum, J. Am. Chem. Soc. 2000, 122, 86408647.

[12] D. R. Hay, Z. G. Song, S. G. Smith, P. Beak, J. Am. Chem. Soc. 1988, 110, 8145-8153.

[13] For recent investigations supporting the formation of complexes on the pathway of directed metalations of some reactants, see: a) F. Affortunato, S. Florio, R. Luisi, B. Musio, J. Org. Chem. 2008, 73, 9214-9220; b) C. Strohmann, V. H. Gessner, Chem. Asian J. 2008, 3, 1929-1934; c) I. Fernandez, J. Gonzalez, F. Lopez-Ortiz, J. Am. Chem. Soc. 2004, 126, 1255112564.

[14] a) J. C. Riggs, K. J. Singh, M. Yun, D. B. Collum, J. Am. Chem. Soc. 2008 130, 13709-13717; b) K. J. Singh, D. B. Collum, J. Am. Chem. Soc. 2006, 128 , 13753-13760; c) S. T. Chadwick, A. Ramirez, L. Gupta, D. B. Collum, J. Am. Chem. Soc. 2007, 129, 2259-2268.

[15] a) D. B. Collum, Accounts Chem. Res. 1992, 25, 448-454; b) X. F. Sun, D. B Collum, J. Am. Chem. Soc. 2000, 122, 2459-2463; c) X. F. Sun, D. B. Collum, J. Am. Chem. Soc. 2000, 122, 2452-2458.

[16] N. J. R. V. Hommes, P. V. Schleyer, Angew. Chem. Int. Ed. 1992, 31, 755 758.

[17] D. W. Slocum, A. Carroll, P. Dietzel, S. Eilerman, J. P. Culver, B. McClure, S. Brown, R. W. Holman, Tetrahedron Lett. 2006, 47, 865-868.

[18] a) R. Maggi, M. Schlosser, Tetrahedron Lett. 1999, 40, 8797-8800; b) M. Schlosser, F. Mongin, J. Porwisiak, W. Dmowski, H. H. Buker, N. M. M. Nibbering, Chem. Eur. J. 1998, 4, 1281-1286; c) M. Schlosser, Angew. Chem. Int. Ed 1998, 37, 1497-1513; d) T. H. Nguyen, N. T. T. Chau, A. S. Castanet, K. P. P. Nguyen, J. Mortier, J. Org. Chem. 2007, 72, 3419-3429.

[19] a) Narasimh.Ns, R. H. Alurkar, Indian. J. Chem. 1969, 7, 1280; b) N. S. Narasimhan, P. S. Chandrachood, Synthesis 1979, 589-590; c) N. S. Narasimhan, R. S. Mali, Tetrahedron 1975, 31, 1005-1009; d) N. S. Narasimhan, P. S. Chandrachood, N. R. Shete, Tetrahedron 1981, 37, 825 827.

[20] M. E. K. Cartoon, G. W. H. Cheeseman, J. Organomet. Chem. 1981, 212, 1-9. 
[21] G. W. H. Cheeseman, S. G. Greenberg, J. Organomet. Chem. 1979, 166, 139 152.

[22] J. M. Fu, B. P. Zhao, M. J. Sharp, V. Snieckus, J. Org. Chem. 1991, 56, 1683 1685.

[23] For reviews on application of DreM in synthesis see: a) C. G. Hartung, V. Snieckus, (Ed.: D. Astruc), Wiley-VCH, New York, 2002, p. 330; b) J. M. Fu, B. P. Zhao, M. J. Sharp, V. Snieckus, Can. J. Chem. 1994, 72, 227-236; c) B. Chauder, L. Green, V. Snieckus, Pure Appl. Chem. 1999, 71, 1521-1529; d) L. Green, B. Chauder, V. Snieckus, J. Heterocyclic. Chem. 1999, 36, 1453-1468; For leading references see: e) S. L. MacNeil, B. J. Wilson, V. Snieckus, Org. Lett. 2006, 8, 1133-1136; f) C. A. James, V. Snieckus, J. Org. Chem. 2009, 74 4080-4093; g) X. W. Cai, V. Snieckus, Org. Lett. 2004, 6, 2293-2295; h) N. Thasana, S. Ruchirawat, Synlett 2003, 1037-1039; i) B. A. Chauder, A. V. Kalinin, N. J. Taylor, V. Snieckus, Angew. Chem. Int. Ed. 1999, 38, 1435 1438.

[24] O. B. Familoni, I. Ionica, J. F. Bower, V. Snieckus, Synlett 1997, 1081-1083.

[25] W. Wang, V. Snieckus, J. Org. Chem. 1992, 57, 424-426.

[26] C. A. James, V. Snieckus, Tetrahedron Lett. 1997, 38, 8149-8152.

[27] L. Benesch, P. Bury, D. Guillaneux, S. Houldsworth, X. Wang, V. Snieckus, Tetrahedron Lett. 1998, 39, 961-964.

[28] M. A. F. Brandao, A. B. Deoliveira, V. Snieckus, Tetrahedron Lett. 1993, 34 , 2437-2440.

[29] B. A. Chauder, A. V. Kalinin, N. J. Taylor, V. Snieckus, Angew. Chem. 1999 $111,1528$.

[30] X. Wang, V. Snieckus, Tetrahedron Lett. 1991, 32, 4883-4884.

[31] X. Wang, V. Snieckus, Tetrahedron Lett. 1991, 32, 4879-4882.

[32] J. Board, J. X. Wang, A. P. Crew, M. Z. Jin, K. Foreman, M. J. Mulvihill, V. Snieckus, Org. Lett. 2009, 11, 5118-5121.

[33] X. Wang, PhD Thesis, University of Waterloo 1992.

[34] a) M. J. Sharp, W. Cheng, V. Snieckus, Tetrahedron Lett. 1987, 28, 50935096; b) W. Cheng, V. Snieckus, Tetrahedron Lett. 1987, 28, 5097-5098; c) D. Tilly, S. S. Samanta, F. Faigl, J. Mortier, Tetrahedron Lett. 2002, 43, 83478350 ; d) D. Tilly, S. S. Samanta, A. S. Castanet, A. De, J. Mortier, Eur. J. Org. Chem. 2005, 174-182.

[35] a) D. Tilly, S. S. Samanta, A. De, A. S. Castanet, J. Mortier, Org. Lett. 2005, 7, 827-830; b) D. Tilly, A. S. Castanet, J. Mortier, Tetrahedron Lett. 2006, 47, 1121-1123.

[36] D. Tilly, J. M. Fu, B P. Zhao, M. Alessi, A. S. Castanet, V. Snieckus, J. Mortier, Org. Lett. 2010, 12, 68-71.

[37] Some electrophiles are compatible with lithium bases at low temperatures (such as $\left.\mathrm{Me}_{3} \mathrm{SiCl}, \mathrm{Me}_{2} \mathrm{Cl}_{2} \mathrm{Si}, \mathrm{B}(\mathrm{O} i \mathrm{Pr})_{3}, \mathrm{~B}(\mathrm{OMe})_{3}\right)$. When lithiation is not complete at the time of addition of the electrophile to the reaction mixture, reaction of the anion with the electrophile is faster than the reaction of the electrophile with the metalating agent. The equilibria are shifted towards the formation of substituted product through kinetic control. For examples see: a) T. D. Krizan, J. C. Martin, J. Am. Chem. Soc. 1983, 105, 6155-6157; b) S. Caron, J. M. Hawkins, J. Org. Chem. 1998, 63, 2054-2055; c) B. H. Lipshutz, M. R. Wood, C. W. Lindsley, Tetrahedron Lett. 1995, 36, 4385-4388.

[38] For properties of LiCKOR see: a) M. Schlosser, Mod. Syn. Met. 1992, 6, 227271; b) M. Schlosser, Pure Appl. Chem. 1988, 60, 1627-1634; c) M. Schlosser, J. H. Choi, S. Takagishi, Tetrahedron 1990, 46, 5633-5648; d) L. Lochmann, Collect. Czech. Chem. Commun. 1987, 52, 2710-2716.

[39] M. E. K. Cartoon, G. W. H. Cheeseman, J. Organomet. Chem. 1982, 234, 123-136.

[40] M. Stratakis, J. Org. Chem. 1997, 62, 3024-3025.

[41] H. F. Bluhm, H. V. Donn, H. D. Zook, J. Am. Chem. Soc. 1955, 77, 44064407.

[42] For hidden proton effect see: a) D. Seebach, Angew. Chem. Int. Ed. 1988, 27, 1624-1654; b) T. Weber, D. Seebach, Helv. Chim. Acta. 1985, 68, 155-161; c) T. Laube, J. D. Dunitz, D. Seebach, Helv. Chim. Acta. 1985, 68, 1373-1393.

[43] M. Alessi, A. L. Larkin, K. A. Ogilvie, L. A. Green, S. Lai, S. Lopez, V. Snieckus, J. Org. Chem. 2007, 72, 1588-1594.

[44] a) S. L. MacNeil, M. Gray, D. G. Gusev, L. E. Briggs, V. Snieckus, J. Org. Chem. 2008, 73, 9710-9719; b) O. Lohse, U. Beutler, P. Funfschilling, P. Furet, J. France, D. Kaufmann, G. Penn, W. Zaugg, Tetrahedron Lett. 2001, 42, 385-389.

[45] S. I. Mohri, M. Stefinovic, V. Snieckus, J. Org. Chem. 1997, 62, 7072-7073.

[46] a) R. R. Fraser, M. Bresse, T. S. Mansour, J. Am. Chem. Soc. 1983, 105, 7790-7791; For relative acidity of hydrogens on heterocycles see: b) O. A Reutov, I. P. Beletskaya, K. P. Butin, CH Acids, Pergamon Press, Oxford, 1978.

[47] C. A. James, A. L. Coelho, M. Gevaert, P. Forgione, V. Snieckus, J. Org Chem. 2009, 74, 4094-4103.

[48] M. Gray, B. J. Chapell, N. J. Taylor, V. Snieckus, Angew. Chem. Int. Ed. 1996, 35, 1558-1560
[49] a) A. S. Rebstock, F. Mongin, F. Trecourt, G. Queguiner, Org. Biomol. Chem. 2004, 2, 291-295; b) J. Epsztajn, A. Jozwiak, J. K. Krysiak, D. Lucka, Tetrahedron 1996, 52, 11025-11036.

[50] G. Queguiner, F. Marsais, V. Snieckus, J. Epsztajn, Adv. Heterocycl. Chem. 1991, 52, 187-304

[51] A. S. Castanet, D. Tilly, J. B. Veron, S. S. Samanta, A. De, T. Ganguly, J. Mortier, Tetrahedron 2008, 64, 3331-3336.

[52] a) J. Fouche, A. Leger, GermanPatent 2,202,486, 1972; Chem. Abstr. 1972, 77, 152012; b) J. Fouche, A. Leger, GermanPatent 2,239,396, 1972; Chem. Abstr. 1972, 77, 152012

[53] For remote remote anionic Fries reactivity see: a) S. L. MacNeil, M. Gray, L. E. Briggs, J. J. Li, V. Snieckus, Synlett 1998, 419; b) Z. Zhao, A. Jaworski, I. Piel, V. Snieckus, Org. Lett. 2008, 10, 2617-2620; c) F. Beaulieu, V. Snieckus, J. Org. Chem. 1994, 59, 6508-6509; d) T. K. Macklin, M. A. Reed, V. Snieckus, Eur. J. Org. Chem. 2008, 1507-1509.

[54] A. S. Rebstock, F. Mongin, F. Trecourt, G. Queguiner, Tetrahedron 2004, 60 , 2181-2186.

[55] D. Tilly, PhD Thesis, University of Maine, 2004

[56] X. W. Cai, S. Brown, P. Hodson, V. Snieckus, Can. J. Chem. 2004, 82, 195205.

[57] A. Streitwieser, F. Guibe, J. Am. Chem. Soc. 1978, 100, 4532-4534.

[58] J. M. Fu, V. Snieckus, Can. J. Chem. 2000, 78, 905-919.

[59] For dilithiation of dibenzofuran see: a) H. D. Wang, F. P. Gabbai, Organometallics 2005, 24, 2898-2902; b) K. Y. Tsang, H. Diaz, N. Graciani, J. W. Kelly, J. Am. Chem. Soc. 1994, 116, 3988-4005; c) H. Gilman, W. J. Trepka, J. Org. Chem. 1961, 26, 5202; d) I. Granoth, C. Symmes, J. B. Levy, J. Chem. Soc. Perk. Trans. II 1972, 697.

[60] A. S. Rebstock, F. Mongin, F. Trecourt, G. Queguiner, Tetrahedron 2003, 59, 4973-4977.

[61] P. Gros, S. Choppin, Y. Fort, J. Org. Chem. 2003, 68, 2243-2247.

[62] X. F. Sun, S. L. Kenkre, J. F. Remenar, J. H. Gilchrist, D. B. Collum, J. Am. Chem. Soc. 1997, 119, 4765-4766.

[63] The transformation of amide $\mathbf{5 1 b}$ to $\mathbf{5 7}$ is a non published result by D. Tilly.

[64] M. L. Parmentier, P. Gros, Y. Fort, Tetrahedron 2005, 61, 3261-3269.

[65] B. D. Palmer, M. Boyd, W. A. Denny, J. Org. Chem. 1990, 55, 438-441.

[66] a) F. Gohier, A. S. Castanet, J. Mortier, J. Org. Chem. 2005, 70, 1501-1504; b) J. Mortier, T. H. Nguyen, D. Tilly, A. S. Castanet, Arkivoc 2007, 47-54

[67] L. A. Crawford, H. Mcnab, A. R. Mount, S. I. Wharton, J. Org. Chem. 2008 73, 6642-6646.

[68] a) A. Chopra, D. C. Dorton, C. A. Ogle, Main Group Met. Chem. 1998, 21, 25-28; b) A. Chopra, D. C. Dorton, C. A. Ogle, Main Group Met. Chem. 1997 20, 783-786.

[69] C. Neumann, A. Schulz, T. Seifert, W. Storch, M. Vosteen, Eur. J. Inorg. Chem. 2002, 1040-1045.

[70] Participation of an electrophile initiated direct remote aromatic metalation to explain DreM of biarylamines using DMF and $\mathrm{CO}_{2}$ cannot be ruled out yet. Reactions of aminolithium with $\mathrm{CO}_{2}$ or DMF during the quenching step could form a new DMG. $N$-carboxylate unit is known to activate subsequent $C$ lithiation steps. For examples see: ) A. R. Katritzky, L. M. V. Demiguel, G. W. Rewcastle, Synthesis 1988, 215-217; b) A. R. Katritzky, M. Black, W. Q. Fan, J. Org. Chem. 1991, 56, 5045-5048; Directing metalation properties of aminoalkoxides have already been described. For examples see: c) D. L. Comins, J. D. Brown, J. Org. Chem. 1984, 49, 1078-1083; d) A. Hallberg, A. Svensson, A. R. Martin, Tetrahedron Lett. 1986, 27, 1959-1962; Ncarboxylate or aminoalkoxide would direct a remote metalation, the remote lithiated species could then be trapped (either through irreversible intramolecular anionic $N$-Fries rearrangement or by dry ice/DMF respectively) to afford the cyclized product.

[71] A. S. Rebstock, F. Mongin, F. Trecourt, G. Queguiner, Org. Biomol. Chem 2003, 1, 3064-3068.

[72] X. Chen, K. M. Engle, D. H. Wang, J. Q. Yu, Angew. Chem. Int. Ed. 2009, 48, 5094-5115.
Received: ((will be filled in by the editorial staff))

Revised: ((will be filled in by the editorial staff)) Published online: ((will be filled in by the editorial staff)) 
$[a]^{*} \quad$ Dr. D. Tilly

Eskitis Institute for Cell and Molecular Therapies

Griffith University

Don Young Road, Nathan 4111, Queensland, Australia

E-mail: dp.tilly@laposte.net

[b] Dr. J. Magolan

Department of Chemistry, University of Idaho

Moscow, ID, USA

[c] Prof. J. Mortier

University of Le Mans UCO2M (UMR CNRS 6011)

Avenue Olivier Messiaen, 72085 Le Mans, Cedex 9, France 
Entry for the Table of Contents (Please choose one layout only)

\section{Layout 1:}

Long-distance directed metalation.

David Tilly*, ${ }^{[a]}$ Jakob Magolan, ${ }^{[b]}$ Jacques Mortier

Directed Remote Aromatic Metalations: Mechanisms and Driving Forces

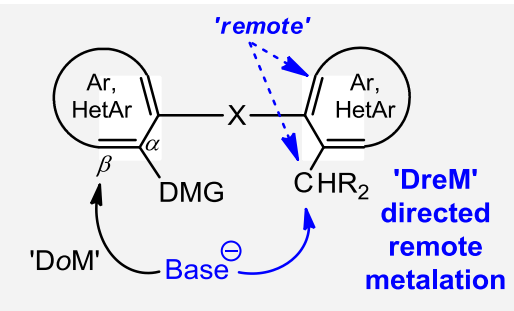

$\mathrm{DMG}=\mathrm{CONR}_{2}, \mathrm{OCONR}_{2}, \mathrm{COR}, \mathrm{CO}_{2} \mathrm{H}$, etc.
Directed remote aromatic metalation is a valuable synthetic tool that has been utilized for the efficient preparation of elaborate aromatic scaffolds. This review tackles the mechanistic nuances and driving forces behind remote metalation in order to unravel the causes of the observed regiochemical outcomes and enable enhanced predictability of these remarkable synthetic transformations. 